\title{
El vicario Alonso de San Cebrián y la Bula de LOS OCHO INQUISIDORES (1474-1482) ${ }^{1}$
}

\author{
José Ma CRuselles Gómez ${ }^{2}$ \\ Universitat de València
}

Recibido: 23 de julio de 2020

Aceptado: 6 de agosto de 2020

\begin{abstract}
Resumen
En la biografía política del dominico Alonso de San Cebrián confluyen dos fenómenos relacionados con la construcción de la monarquía hispánica a finales del siglo XV. Por una parte, la reforma de las órdenes religiosas con la expansión de las congregaciones de la observancia regular; por otra, el nacimiento de la nueva Inquisición. Hombre de acción e ideología extremista, San Cebrián fue un destacado reformador religioso cuyas importantes conquistas prepararon el triunfo definitivo de la Congregación de la Observancia dominicana en Castilla. Contó con la colaboración de los Reyes Católicos, imprescindible para someter a la oposición, sin reparar en la violencia de los medios. En contrapartida, además de facilitar el control de su orden por la Corona, el vicario prestó importantes servicios diplomáticos en Roma, entre ellos la obtención de la bula pontificia que dio origen a la carrera de Torquemada como inquisidor general.
\end{abstract}

\section{Palabras clave}

Dominicos. Observancia. Inquisición Española. Torquemada. Reyes Católicos.

\begin{abstract}
In the political biography of the Dominican Alonso de San Cebrián, two phenomena related to the construction of the Hispanic monarchy at the end of the 15th century converge. On the one hand, the reform of religious orders through the expansion of the Observant Congregations; on the other hand, the birth of the new Inquisition. A man of action and extremist ideology, San Cebrián was a prominent religious reformer whose important conquests paved the way for the ultimate triumph of the Dominican Observant Congregation in Castilla. He had the collaboration of the Catholic Monarchs, indispensable to subdue the opposition, regardless of the violence of the means. In return, besides facilitating the
\end{abstract}

1 Este trabajo forma parte de los resultados del proyecto "Desigualdad económica y movilidad social en la Europa mediterránea (siglos XIII-XVI)”, GVPROMETEO2019-072, financiado por la Generalitat Valenciana.

Abreviaturas: ACA RC = Archivo de la Corona de Aragón, sección de Real Cancillería; AGS RGS = Archivo General de Simancas, sección Registro General del Sello; AHN = Archivo Histórico Nacional; col. = columna; $\mathrm{n} .=$ nota.

2 Departament d'Història Medieval i CC.TT. Historiogràfiques. Universitat de València. Correo electrónico: jose.m.cruselles@uv.es. ORCID: https://orcid.org/0000-0002-7829-4219. 
Crown's control over his order, the vicar provided important diplomatic services in Rome, including the obtention of the papal bull that gave rise to Torquemada's career as general inquisitor.

\title{
Keywords
}

Dominicans. Observants. Spanish Inquisition. Torquemada. Catholic Monarchs.

\begin{abstract}
Resum
En la biografia política del dominicà Alonso de San Cebrián conflueixen dos fenòmens relacionats amb la construcció de la monarquia hispànica a finals del segle XV. Per una part, la reforma dels ordes religiosos amb l'expansió de les congregacions de l'observança regular; per altra, el naixement de la nova Inquisició. Home d'acció i ideologia extremista, San Cebrián va ser un destacat reformador religiós les conquestes del qual van preparar el triomf definitiu de la Congregació de la Observança dominicana a Castella. Va comptar amb la col·laboració dels Reis Catòlics, necessària per a sotmetre l'oposició, sense reparar en la violència dels mitjans emprats. Com a contrapartida, a més de facilitar el control del seu orde per la Corona, el vicari prestà importants serveis diplomàtics a Roma, entre els quals l'obtenció de la butlla pontifícia que va donar origen a la carrera de Torquemada com a inquisidor general.
\end{abstract}

\section{Paraules clau}

Dominicans. Congregació observant. Inquisició espanyola. Torquemada. Reis Catòlics.

A finales de 1483 la cancillería real aragonesa preparó dos formularios para que Tomás de Torquemada, prior del convento dominico de Santa Cruz de Segovia, pudiera designar por primera vez inquisidores delegados en las coronas de Aragón y de Castilla. ${ }^{3}$ En el primer caso se incluyó, a modo de justificación, un breve fechado el 17 de octubre anterior en el que Sixto IV designaba a Torquemada inquisidor general de Aragón, Cataluña y Valencia. ${ }^{4}$ En el segundo, la bula con la que dicho pontífice había nombrado, el 11 de febrero de 1482, ocho inquisidores para los reinos de Castilla y León, entre los cuales -ni siquiera en un lugar destacado- estaba Torquemada. ${ }^{5}$ El breve de 1483 otorgaba expresamente al beneficiario la capacidad de delegar su autoridad, pero no así la bula de 1482, cuyo uso para semejante propósito era, en consecuencia, ilegal. ${ }^{6}$ Este hecho ha desconcertado a algunos historiadores de la Inquisición, que para explicarlo han recurrido a un argumento ad hoc: "por ese tiempo más o menos" el papa nombró inquisidor general de Castilla a Torquemada, pero el documento se ha perdido o no ha sido descubierto todavía. ${ }^{7}$

Sin embargo, no es fácil explicar por qué existiendo para Castilla un nombramiento posterior e idóneo en términos jurídicos, la cancillería recurrió a una bula que había

\footnotetext{
SESma, Fernando II y la Inquisición, pp. 58-59. Ambos documentos han sido publicados en TorRe, Documentos, pp. 387-391.

4 Martínez Díez, Bulario, pp. 158-159.

IBIDEM, pp. 92-95.

6 Azcona, Isabel la Católica, p. 403, n. 89, advertía ya acerca del uso indebido que se hizo de dicha bula en Castilla "para el oficio de inquisidor mayor y su empleo en los nombramientos subdelegados".

7 Meseguer, "El periodo fundacional", p. 311, n. 77.
} 
quedado obsoleta, mientras para la Corona de Aragón utilizaba el breve de octubre de 1483, que cronológicamente habría de ser posterior al desaparecido de Castilla, pues se supone que Torquemada fue antes inquisidor general de esta y después de aquella. De momento y hasta que aparezca la bula perdida, parece más razonable pensar que nunca existió, y que los secretarios del rey utilizaron lo que tenían a su alcance para proporcionar cobertura legal -o apariencia de ella- a los tribunales inquisitoriales creados en los últimos meses de 1483 y primeros de 1484. De hecho, tampoco era la primera vez que la cancillería aragonesa usaba las concesiones pontificias de manera inadecuada, aunque oportunista, para apuntalar la jurisdicción inquisitorial en momentos decisivos. ${ }^{8}$ Podemos afirmar, por tanto, que fue la bula Dudum felices, otorgada por Inocencio VIII el 3 de febrero de $1486,{ }^{9}$ la que inequívocamente convirtió a Torquemada en inquisidor general único de Castilla y Aragón, incluyendo la autoridad para nombrar delegados, inédita en Castilla, donde hasta ese momento no tenía otro soporte jurisdiccional que la bula de los ocho inquisidores.

No deja de resultar sorprendente la escasa atención que este documento ha merecido por parte de los historiadores de la Inquisición española; tal vez porque, como he señalado, se ha preferido pensar que representaba un estadio transitorio y poco significativo en el camino hacia el verdadero aunque desaparecido nombramiento de Torquemada para Castilla, que debía ser en todo similar al otorgado en octubre de 1483 para la Corona de Aragón pero cronológicamente anterior. Si, por el contrario, reconsideramos su trascendencia en el proceso de gestación institucional del Santo Oficio, la bula de 1482 y las condiciones en que fue obtenida cobran mucho mayor interés.

Solo tres aspectos han llamado hasta ahora la atención de los estudiosos, que en orden a la importancia que se les ha concedido son los siguientes: a) entre los ocho inquisidores designados en 1482 por Sixto IV para los reinos de Castilla y León se encontraba Torquemada; b) todos los integrantes del grupo eran miembros de la orden de predicadores; y c) la bula se había obtenido merced a los buenos oficios diplomáticos de otro de sus beneficiarios, Alonso de San Cebrián, que en aquel momento era el vicario general, es decir, el máximo dirigente de los conventos dominicos castellanos integrados en la llamada Congregación de la Observancia.

\footnotetext{
8 Sobre la justificación del nombramiento de los inquisidores de Valencia a finales de 1481 recurriendo a la bula Exigit sincerae devotionis de 1478, véase CRuSELlES, "Llegan los inquisidores”, pp. 109-136.

9 Martínez Díez, Bulario, pp. 168-171. En algunos lugares se adelanta su fecha a 1485, sin tener en cuenta que su datación responde al estilo florentino del año de la encarnación. La potestas substituendi, imprescindible para crear una jerarquía inquisitorial centralizada y extensa, no aparece propiamente en ninguna de las concesiones pontificias otorgadas a los monarcas hispanos por el papa o el maestro general de la orden dominica con anterioridad al nombramiento de Torquemada como inquisidor general de la Corona de Aragón, el 17 de octubre de 1483. Solo en una ocasión se dio lugar a algo parecido. El 18 de septiembre de 1481 Salvo Cassetta, maestro general de la orden de predicadores, delegó en un miembro de dicha orden, Gaspar Jutglar, del convento de Lérida, la función de nombrar y deponer inquisidores en la Provincia Dominicana de Aragón, siempre que se atuviera a las personas designadas por Fernando II. Casi a renglón seguido el monarca, sobrepasando abusivamente sus atribuciones, nombró a dicho Jutglar inquisidor general de dicha provincia (TorRe, Documentos, pp. 182-183; ACA RC 3606, ff. 132v-133v).
} 
Como indica el título elegido para este trabajo, abundaremos en el último de estos hechos y de manera más general en la relación establecida, en torno al origen del Santo Oficio, entre la monarquía de los Reyes Católicos y la Congregación de la Observancia, en cuyas filas militaba la mayor parte de los inquisidores que la Corona puso al frente de los tribunales creados entre 1480 y 1484 . Reconstruir la trayectoria de Alonso de San Cebrián como reformador religioso y diplomático nos permitirá comprender mejor aquella primera etapa constituyente. Para esta tarea contamos con informaciones dispersas, aunque numerosas, publicadas sobre todo por autores cuyo propósito era ofrecer -con fines a menudo encomiásticos, aunque no necesariamente- la historia de la orden dominicana y de la reforma observante a finales del siglo XV. Nuestro trabajo ha consistido en reunirlas, ordenarlas y proponer, hasta donde resulte posible, algunas explicaciones.

\section{Orígenes de la observancia dominicana en Castilla}

En 1475, en plena escalada del conflicto sucesorio castellano, también la llamada Provincia Dominicana de España -que integraba los territorios de la corona castellanoleonesa- se encontraba dividida por un grave enfrentamiento interno que, como la disputa por el trono, venía gestándose en las décadas anteriores. Aunque con demora respecto a benedictinos y franciscanos, los dominicos no habían quedado al margen de las iniciativas de reforma del clero regular difundidas, desde finales del siglo XIV, como parte de la reacción contra los males que aquejaban a una Iglesia sumida en la confusión del cisma. El remedio propuesto, regresar a las condiciones de vida comunitaria recogidas en las reglas primigenias de cada orden, en buena medida caídas en desuso, dio lugar al llamado movimiento observante..$^{10}$ En primera instancia, las propuestas de los clérigos reformistas se materializaron en la proliferación de grupos eremíticos y místicos que en Castilla recibieron el amparo de Juan I (1379-1390), quien compartía su diagnóstico sobre los males de la Iglesia y veía con buenos ojos el retorno a la vieja piedad monástica. ${ }^{11}$ Las simpatías despertadas en todos los niveles de la sociedad favorecieron la multiplicación de las iniciativas, aunque sin dotarse nunca de una organización institucional que permitiera, más allá de la fundación de cenobios y del carisma personal de sus virtuosos promotores, trascender la dispersión característica del movimiento. ${ }^{12}$

10 La reforma de los monasterios fue uno de los "movimientos de reforma evangélica y jerarquizada identificados con el gran clamor de la reforma en la cabeza y en los miembros". A partir de las últimas décadas del siglo XIV, una parte del clero regular tenía la percepción de que las diferentes órdenes, incluidas las mendicantes, estaban sumidas en una situación de profunda decadencia material y moral que se intentó superar con una acción reformista que Azcona califica de "espontánea", cuya finalidad era "volver al vigor de los orígenes mediante la observancia rígida y a la letra de las reglas iniciales y los ideales de sus fundadores" (AzCONA, "La reforma religiosa", pp. 124-126).

11 García Oro, "Conventualismo y observancia", pp. 234-237; Nieva, "La creación de la observancia regular", p. 92, afirma que su acción reformista "permitió a la monarquía capitalizar una experiencia y acuñar una ideología que conocería un éxito prolongado, más allá de las expectativas de sus promotores".

12 García Oro, "Conventualismo y Observancia", pp. 237-244. 
Sin embargo, aprovechando las expectativas creadas por el eremitismo y en medio de la agitación doctrinal que rodeaba el movimiento conciliar, comenzaron a gestarse en las primeras décadas del siglo XV las reformas disciplinares que luego dieron lugar a las llamadas congregaciones de observancia. Estas, más allá de la estrategia obvia de presentarse a sí mismas como dechado de virtudes cenobíticas, aspiraban a corregir activamente a los demás frailes, obligándoles -si era necesario por la fuerza, pero siempre por su propio bien- a recuperar el género de vida prescrito originalmente para ellos. Los "observantes", que se consideraban sobradamente legitimados por sus grandilocuentes declaraciones de fidelidad a los padres fundadores, se lanzaron a la conquista de las respectivas órdenes mediante una reforma corporativa que incluía, como no podía ser menos, un nuevo reparto del poder. ${ }^{13}$

Los avances de la observancia dominicana en Castilla fueron bastante lentos en comparación con los de otras órdenes religiosas, como franciscanos o jerónimos. Hacia 1440, según las cuentas de Beltrán de Heredia, no pasaban de cinco los conventos adscritos a una reforma de corte eremítico que, tras la experiencia inicial del beato Álvaro de Córdoba y la fundación del convento de Escalaceli hacia 1423, tuvo poco éxito en la orden de los predicadores porque dificultaba la predicación, su seña identitaria. En 1436 uno de estos conventos dominicos reformados, el de Murcia, consiguió un privilegio pontificio que lo desligaba de la autoridad del fraile que gobernaba la Provincia, el llamado prior provincial. La medida supuso un avance pionero en el camino que conduciría al nacimiento de la Congregación de la Observancia. ${ }^{14}$ Otro medio para extender la reforma consistió en imponerla de manera expeditiva. El primer caso que hemos podido recoger fue protagonizado por fray Rodrigo de Valencia, ${ }^{15}$ antiguo confesor del rey Enrique III de Castilla y discípulo del beato Álvaro de Córdoba, que en 1440 intentó obtener del papa Eugenio IV poderes para reformar el convento de San Pablo de Sevilla contra el criterio del maestro general de la orden, quien frustró la maniobra. ${ }^{16}$

A partir de mediados del siglo XV el conflicto se recrudeció. Las nacientes congregaciones de observancia, viendo en juego su propia existencia, recurrieron a medios cada vez más agresivos para expandirse, lo que atizaba a su vez una enconada defensa

\footnotetext{
13 IBIDEM, p. 247; GARCÍA ORO, "La reforma religiosa y su repercusión", p. 1113.

14 Beltrán, "Los comienzos", pp. 403-406; Pérez Vidal, "Observancia y rigorismo", p. 801.

15 No confundir con el prior homónimo del convento de San Benito de Valladolid, que fue asesinado en 1499 junto con otros compañeros cuando intentaba sujetar a la Congregación observante benedictina los pequeños y dispersos monasterios gallegos (Colombás, Las señoras de San Payo, pp. 33-48; GarCía Oro, "La reforma de los monasterios gallegos", pp. 47-55).

16 Al parecer, la concesión pontificia exigía el consentimiento del maestro general, que fray Rodrigo prefirió no solicitar. Además, Beltrán de Heredia sospecha que, para lograr sus fines, el reformador dominico exageró el estado de postración en que se encontraba la observancia regular en Sevilla (BELTRÁN, "Los comienzos", p. 407), lo que unido al hecho de que residiera en el mismo convento de San Pablo que pretendía reformar, convierte este episodio en algo muy parecido a una lucha de poder. Finalmente, la vocación reformadora del discípulo del beato Álvaro se vio recompensada cuando, con posterioridad a 1452, dejó dicho convento para fundar en esa misma ciudad de Sevilla el de Santo Domingo de Portaceli, sobre un oratorio que su maestro había creado años antes (Miura, "La Provincia Bética", pp. 29-30).
} 
por parte de las autoridades provinciales. ${ }^{17}$ En el caso de los franciscanos la victoria se decantó relativamente pronto del lado de los observantes ${ }^{18}$ pero entre los dominicos una jerarquía mucho más autoritaria consiguió mantener el movimiento bajo control. Sin embargo, la presión aumentaba. En 1454 fue procesado y destituido el provincial Esteban Soutello, a quien el papa y otros poderosos prelados achacaban la decadencia que padecía la vida comunitaria en la Provincia, así como otros delitos de corrupción. En opinión de Beltrán de Heredia las acusaciones respondían a la realidad de los hechos, pero también expresaban el conflicto abierto por controlar la orden, como parece confirmar la circunstancia de que fueran condenados, junto con Soutello, "otros religiosos que se oponían a la reforma de la provincia". ${ }^{19}$

El establecimiento de una congregación observante en la Provincia Dominicana de España fue obra del cardenal Juan de Torquemada, dominico él mismo, que la asoció a la reforma del convento de San Pablo de Valladolid, efectuada entre 1459 y 1462. Torquemada contó para ello con la colaboración del papa Pío II, el ejemplo de la Congregación de la Observancia de Lombardía y, sobre el terreno, con la experiencia de los reformadores benedictinos locales, a quienes él mismo había apoyado previamente. Los medios que puso en práctica para vencer la resistencia del convento y de las autoridades provinciales fueron realmente contundentes. Desde Italia llevó hasta Valladolid a algunos frailes castellanos que habían abrazado allí la observancia, e incluso trajo al propio maestro general de la orden, Marcial Auribelli, quien en 1459, antes de emprender el viaje, otorgó poderes al dominico Antonio de Santa María de Nieva para llevar a cabo la reforma del convento de San Pablo, destituir al prior y expulsar a los frailes díscolos. No fue suficiente y en 1460 Torquemada recurrió al prior del monasterio de San Benito de Valladolid, Juan de Gumiel, que gozaba de la considerable ventaja de ser ajeno a la estructura jerárquica de la orden dominicana.

Imponer a un benedictino, aunque fuera temporalmente, como regente de un convento dominico era algo lo bastante extraño como para precisar una confirmación pontificia que Pío II se apresuró a otorgar el 15 de noviembre de 1460, mediante una bula que ratificaba la autoridad de fray Antonio como vicario de la reforma y convertía a Gumiel en su asistente, con poderes para recurrir a la fuerza si era necesario. Pero como esto tampoco hizo desistir la oposición, el papa lanzó en agosto de 1461 otra batería de medidas que eximían al vicario Nieva de la jurisdicción provincial de la orden, extendían al cenobio vallisoletano los privilegios de la Congregación de Lombardía y reforzaban

\footnotetext{
17 Las incapacidad de ambas partes para imponerse dio lugar a las llamadas "bulas de concordia", que imponían el respeto mutuo y prohibían ocupar conventos y coaccionar a los frailes para incorporarlos a un grupo u otro (GARCíA Oro, "Conventualismo y observancia", p. 231).

18 El número de conventos observantes franciscanos, inferior a una decena en 1434, superaba los sesenta en 1477 gracias sobre todo a las nuevas fundaciones patrocinadas por la Corona, la nobleza y los municipios, resultado a su vez de la devoción que el movimiento despertaba entre los laicos (IBIDEM, p. 256).

19 Beltrán, "Los comienzos", pp. 409-412.
} 
las atribuciones de Gumiel. Por último, un capítulo conventual convenientemente depurado eligió nuevo prior y recibió la visita del maestro general en marzo de $1462 .{ }^{20}$

Una vez en Valladolid, Auribelli ratificó los privilegios pontificios, confirmó la actuación de los reformadores, amplió sus competencias represivas y amonestó duramente a quienes aún se oponían a los planes del cardenal Torquemada. A renglón seguido regresó a Italia para asistir al capítulo general de la orden, que tuvo lugar en Siena el siguiente mes de agosto, y allí Pío II lo destituyó a instancias de la cada vez más poderosa Congregación de Lombardía, sin que le sirviera de nada su evidente celo reformista. Los observantes habían conseguido cobrarse la cabeza misma de la orden. ${ }^{21}$

El conflicto se enconaba. En Valladolid, hacia mediados de 1463, Juan de Gumiel consiguió rechazar con la ayuda de la población un intento de los frailes expulsados para recuperar el convento al asalto. Poco después restituyó el control al nuevo prior. Al año siguiente, el capítulo provincial celebrado en Córdoba tomó medidas para asegurar la correcta observancia de la regla en los conventos de la orden, tal vez con la esperanza de evitar que le fueran impuestas nuevas reformas desde el exterior. Esta voluntad reformadora de las autoridades provinciales tuvo relativo éxito, ya que en los años siguientes ningún otro convento dominico pasó a manos de la Congregación, pero a largo plazo la expansión de esta resultaba inevitable. En 1467, en medio de la guerra desatada entre Enrique IV y el infante Alfonso, Marcial Auribelli regresó a Castilla tras haber sido repuesto dos años antes en el generalato de la orden. ${ }^{22}$ A pesar del agrio enfrentamiento con los observantes lombardos, no había decaído un ápice su compromiso con el cardenal Torquemada - promotor también de este segundo viaje- y por extensión con la Congregación castellana, a la que ahora dotó de naturaleza jurídica creando el cargo de vicario general de la reforma, con atribuciones para gobernar todos los conventos dominicos que hubieran abrazado o abrazaran en el futuro la observancia. La maniobra tuvo un inmediato éxito político, pues ambos contendientes al trono se apresuraron a ofrecer apoyo al nuevo vicario "para que reduzca todas las casas a la observancia". ${ }^{23}$

Considerando que Auribelli no llegó a eximir completa y expresamente al nuevo vicario de la jurisdicción del prior provincial, Beltrán de Heredia pone en duda que los observantes castellanos pudieran en aquel momento elegirlo por sí mismos, como establecían los privilegios de la Congregación de Lombardía que el maestro general les había otorgado. Supone, por el contrario, que Auribelli intentó eludir el conflicto abierto entre la Provincia y la Congregación eligiendo personalmente al vicario, lo que habría hecho antes de regresar a Italia. En cualquier caso, nada sabemos de aquel primer

\footnotetext{
20 NiEva, "Reformatio in membris", pp. 303-310, hace una detallada reconstrucción de estos hechos a partir, fundamentalmente, de los documentos publicados en su día por Beltrán de Heredia.

${ }_{21}$ Antes que a su simpatía por los intereses franceses en Italia, que sin duda pudo ganarle la malquerencia del sienés Pío II, Mortier sostiene -tomando en consideración los acontecimientos posteriores- que la verdadera causa de la destitución de Auribelli fue haber intentado poner coto a la autonomía de los observantes lombardos (MorTIER, Histoire, pp. 391-396).

22 IBIDEM, pp. 417-420.

23 Beltrán, Historia, pp. 11-14.
} 
vicario de la observancia, ni tan solo si hubo más de uno entre 1467 y 1472, fecha esta última en la que Juan de San Martín desempeñaba el cargo. ${ }^{24}$

Es importante insistir en que la Congregación de la Observancia no fue el único movimiento reformador de la orden dominicana en el siglo XV. En realidad, fue el más tardío de cuantos se produjeron durante esa centuria, aunque también el más agresivo. El más temprano, de naturaleza eremítica y carente de organización institucional propia, fue controlado sin dificultad por las autoridades provinciales. ${ }^{25}$ Sin embargo, y según afirma Beltrán de Heredia, aquella experiencia inspiró un segundo impulso reformador promovido por los propios órganos de gobierno de la orden que, mediante sucesivas disposiciones adoptadas en los capítulos provinciales desde 1434, pretendieron asegurar la observancia de la regla en los conventos. El progreso de esta reforma "desde arriba" dio lugar a iniciativas particulares en comunidades como Santa María de Nieva en 1439 y San Esteban de Salamanca en 1453; también a conflictos como la mencionada destitución del provincial Soutello en $1454 .{ }^{26}$ Esta corriente reformista, que gobernaba la Provincia cuando apareció la Congregación, sería precisamente la que a partir del siglo XVI los cronistas dominicos comenzaron a calificar como "la peste de la Claustra". ${ }^{27}$

\section{Un reformador enérgico}

Las primeras noticias que tenemos de Alonso de San Cebrián ya lo sitúan en los niveles superiores del gobierno de la orden. Fraile profeso del convento de San Ildefonso de Toro, ${ }^{28}$ ejerció como prior de San Esteban de Salamanca entre 1470 y 1473, cuando dejó el cargo movido, a decir de algunos cronistas, por su compromiso con la observancia. ${ }^{29}$ El 19 de julio de 1474, siendo prior del convento de San Pablo de Burgos, que debió

\footnotetext{
24 IBIDEM, p. 14. Hay algunos indicios, a los que después haremos referencia, de que ese primer vicario de la Congregación pudo ser el propio Alonso de San Cebrián.

25 García Oro, "Conventualismo y observancia", p. 220. No así por la Congregación de la Observancia, a la que opondría más adelante una fuerte resistencia. De hecho, el convento de Escalaceli, fundación emblemática del beato Álvaro de Córdoba, no se integró en la Congregación hasta 1489, cuando ya lo habían hecho los principales conventos "claustrales" (BELtrán, Historia, pp. 3-4).

26 IBIDEM, pp. 4-5; Beltrán, "Los comienzos”, pp. 411-412.

27 La asociación entre la Peste Negra de 1348 y el régimen administrativo previo al triunfo de la observancia, supone un lugar común para frailes historiadores como el valenciano Francisco Diago, que a finales del siglo XVI describía la Claustra como "pestilencia de almas" (Diago, Historia, f. 40r, col. B). Nieva Ocampo da cuenta de la creación de este tópico, nacido de la purga ideológica y documental llevada a cabo por la Congregación, y cuestiona la existencia misma de aquel desorden generalizado de la moral y la disciplina (NIEva, "Reformatio in membris", pp. 327-330).

28 López, Tercera parte, p. 310.

29 Nieva, "Reformatio in membris", p. 318. Otros afirman que también había sido prior del convento de San Pablo de Valladolid, aunque sin señalar en qué momento (Cuervo, Historiadores, vol. I, p. 310). En 1479, cuando era vicario general de la observancia, una carta del maestro general de la orden lo identificaba como miembro del convento de Valladolid (Beltrán, Historia, p. 233).
} 
incorporarse por aquellas fechas a la Congregación, ${ }^{30}$ el nuevo maestro general Leonardo Mansuetis lo nombró juez en el conflicto que enfrentaba al prior provincial Andrés de Toro "con algunos de sus súbditos". ${ }^{31}$ Semejante decisión no deja de sorprender, dado que San Cebrián se convertiría - probablemente ya lo era- en uno de los detractores más tenaces de fray Andrés.

Poco antes, en Roma, Andrés de Toro había tomado parte en el capítulo general de la orden que, el 29 de mayo de 1474, otorgó el generalato a Mansuetis. Este, en un primer momento, intervino a su favor en el conflicto con la Congregación castellana, cuyas prerrogativas derogó el 15 de junio al tiempo que cesaba al vicario general Juan de San Martín y a los priores de los conventos reformados, poniendo la provisión de todos esos cargos en manos del provincial. Sin embargo, el maestro general cambió de opinión al día siguiente y, aunque no derogó su anterior mandato, lo sometió a la aceptación previa de San Martín y los observantes, lo que a efectos prácticos resultaba equivalente. El 7 de julio el general abundaba en la confusión declarando, por una parte, que el vicariato de la Congregación era un cargo trienal y estaba sometido a ratificación del provincial, aunque San Martín -cuyo trienio probablemente había concluido- debía seguir ejerciéndolo mientras no se designara un sustituto; y por otra, que si los observantes rechazaban las nuevas ordenaciones de la Congregación continuarían vigentes las anteriores. Por contra, el 2 de noviembre, Mansuetis prohibió al vicario San Martín reformar convento alguno sin la conformidad expresa del provincial y de la mayor parte de la comunidad afectada. De esta manera, ni las autoridades provinciales tenían capacidad para someter a la Congregación, pues la normativa aprobada en el capítulo general de la orden no podía entrar en vigor, ni los observantes podían ampliar su influencia, limitados como estaban por las prerrogativas del provincial y la necesidad de generar consensos previos en los conventos a reformar. Sin embargo, a finales de 1474 el equilibrio comenzaba a romperse. Sin que sepamos si la decisión respondió a un proceso electoral previo en el seno de la Congregación, el día 30 de noviembre Mansuetis nombró vicario general de la observancia a Alonso de San Cebrián. ${ }^{32}$

Podemos pensar que en aquellos primeros compases de su mandato el nuevo maestro general de los dominicos no tenía claro hacia qué lado decantarse. Temía que las congregaciones observantes provocaran la escisión en la orden, pero tampoco ignoraba las consecuencias que había tenido el enfrentamiento entre su predecesor y los reformadores lombardos. En este sentido, sus disposiciones contradictorias tenían la virtud de dar satisfacción inmediata a cada peticionario manteniendo a la vez el statu

\footnotetext{
30 Beltrán de Heredia lo incluye entre la decena de conventos que formaban parte en 1478 de la Congregación de la Observancia dominicana, que había experimentado un fuerte impulso tras el ascenso al trono de Isabel y Fernando (IBIDEM, p. 16).

31 IBIDEM, p. 38.

32 Mortier, Histoire, pp. 515-516. Según el resumen incluido en los registros del archivo del maestro general de los dominicos, que es todo lo que conservamos de esta documentación, en esa fecha San Cebrián fue nombrado vicario general "de nuevo", lo que podría significar que ya había ocupado el cargo antes de 1472, lo que a su vez explicaría que el capítulo provincial, al notificar su defunción en 1493, lo considerara primer vicario general y fundador de la Congregación (véanse infra, n. 115 y 116).
} 
quo. En 1475 seguía perseverando en este complicado juego de contrapesos. Si el año anterior otorgaba poderes a San Cebrián para entender en un pleito en el que había de ser juez y parte, dado su más que presumible enfrentamiento con el provincial Andrés de Toro, el 24 de julio de 1475 nombró un vicario o delegado para gobernar la Provincia, lo que equivalía a destituir al provincial o, al menos, a dejar su autoridad en suspenso. El elegido fue Pedro González de la Torre, fraile del convento de Burgos del que San Cebrián era prior antes de convertirse en vicario general de la observancia. Fray Pedro había viajado personalmente a Roma para obtener el citado nombramiento junto con otras prebendas personales, pero Mansuetis, fiel a su método, lo anuló el día 2 de noviembre tras ser advertido por Andrés de Toro de la falsedad de las acusaciones vertidas contra él. ${ }^{33}$

Con la elección de San Cebrián como vicario general, el enfrentamiento entre los observantes y las autoridades provinciales devino en una guerra abierta que dio al traste con el difícil equilibrio que Mansuetis intentaba salvar. En algún momento, hacia finales del verano o ya en el otoño de 1475, fray Pedro de la Torre regresó de Italia con su nombramiento de vicario provincial y declaró destituido a Andrés de Toro. ${ }^{34}$ Es probable que este ya hubiera apelado al maestro general y conseguido que se revocaran los poderes de fray Pedro, pero fue necesario volver a pedir que la destitución del provincial y las demás actuaciones del efímero vicario fueran expresamente anuladas. Esa segunda declaración no se produjo hasta el 20 de enero de $1476,,^{35}$ de manera que la maniobra no consiguió acabar con Andrés de Toro, pero creó en las instituciones provinciales una situación de caos y vacío de poder que favorecía los planes de San Cebrián.

En la madrugada del día 20 de diciembre de 1475, al frente de un grupo de frailes "llamados en este reino vulgarmente observantes" y apoyado por el corregidor de la ciudad, que traía gente armada, Alonso de San Cebrián entró subrepticiamente en el convento de San Esteban de Salamanca, "que les fue dada la llave con engaño", capturó a los monjes y se encerró en su interior. El episodio, recogido en acta notarial unas semanas después, dio paso a una auténtica batalla que se libró en el claustro y las dependencias del convento, tras congregarse la población a toque de campana para defender el cenobio

\footnotetext{
33 Beltrán de Heredia acaba perdiendo la paciencia ante tanta rectificación y afirma que Mansuetis carecía del carácter necesario para imponerse a las "pasiones de algunos inquietos" (BeltrÁn, Historia, p. 38).

34 No debe confundirse el cargo de vicario general de la provincia con el de vicario general de la observancia. Este último tenía carácter ordinario y su cometido era, como hemos visto, gobernar los conventos reformados. El de vicario provincial era, por contra, un cargo extraordinario y transitorio. Cuando el prior provincial cesaba en sus funciones por muerte o destitución, se designaba un vicario general de la provincia que solía ser el prior del convento donde estaba convocado el siguiente capítulo provincial. También podía ser designado por el maestro general, como en este caso. Su cometido era asegurar la elección del nuevo prior provincial y decaía en sus funciones inmediatamente después. Sin embargo, era frecuente que, celebrándose la elección en el convento de residencia del vicario provincial, este consiguiera hacerse con ella (Waltz, Compendium, pp. 86-87; Diago, Historia, f. 72r, col. B).

35 Beltrán, Historia, p. 38, n. 3. El apoyo de la Corona todavía se retrasó más, tal vez para dejar constancia de la desgana con que se ofrecía. Hasta el 29 de diciembre de 1476 no desautorizó la reina Isabel a Pedro González de la Torre, ordenando obedecer a Andrés de Toro como verdadero prior provincial de los dominicos castellanos (Beltrán, "Los comienzos", p. 422).
} 
y entrar "por las paredes y huertos más de mil hombres armados". Aunque el corregidor intentó hacer frente a la avalancha y "quebró la vara a palos al alguacil en la cabeza", los asaltantes estaban en inferioridad numérica y hubieron de retirarse hasta la iglesia, donde se hicieron fuertes esperando un ataque final que no llegó a producirse porque se interpusieron algunas personas sensatas, entre ellas el obispo de Orense y una dama de la nobleza local. Expulsados finalmente del convento, San Cebrián y sus frailes se refugiaron primero en una iglesia cercana, "e aun allí les querían matar", siendo acogidos por los franciscanos antes de salir finalmente de la ciudad. Por su parte, el corregidor terminó abandonando San Esteban con su tropa, lo que puso fin a la escaramuza. ${ }^{36}$

Sin duda, la elección de San Cebrián como vicario de la observancia contribuyó a la radicalización del movimiento y al uso de la violencia, pero no fue su única causa ni quizás la más importante. Es probable que los hechos de Salamanca no se hubieran producido de la misma forma sin el clima de guerra civil que se vivía en el país, y en particular sin la connivencia de uno de los bandos en conflicto. De hecho, San Cebrián había prestado previamente algunos servicios diplomáticos a la reina Isabel en relación con el comienzo de las hostilidades. ${ }^{37}$ Salamanca, desgarrada por la lucha de facciones, era una plaza importante para los isabelinos por su cercanía a Portugal, que proporcionaba apoyo militar al enemigo. Por otra parte, San Esteban era uno de los grandes conventos de la orden dominicana y, más allá de que el detestado Andrés de Toro fuera su hijo de hábito, o de su secular rivalidad con el de San Pablo de Valladolid, cuna de la Congregación, era su prestigio como centro de estudios lo que justificaba el interés que los observantes sentían por él, pues su conquista podía facilitar la de otros cenobios. En este sentido, los reyes y San Cebrián tenían motivos sobrados para entenderse. ${ }^{38}$

36 El documento, fechado en Salamanca el 6 de febrero de 1476, fue recogido en la "Historia del Convento de San Esteban" que José Barrio escribió a principios del siglo XVIII y Justo Cuervo publicó doscientos años más tarde (CuERvo, Historiadores, vol. II, pp. 488-491).

37 Pasó a Portugal, junto con otros, a fin de recabar para la causa isabelina el apoyo de algunos nobles contrarios a los proyectos belicistas de Alfonso V (SuÁrez, Política internacional, vol. I, p. 91).

38 Sobre la importancia estratégica de Salamanca para los reyes y del convento de San Esteban para los observantes, véase NIEVA, "Reformatio in membris", pp. 320-324; y sobre el viejo conflicto entre los conventos de Salamanca y Valladolid, que se remontaba al menos a comienzos del siglo XV, BELTRÁn, Historia, pp. 20-24. El efecto que la incorporación del convento de Salamanca hubiera tenido para la Congregación castellana -en una orden que hacía de los estudios teológicos una seña de identidad- podría asimilarse al que tuvo para la Congregación lombarda la anexión del convento de Santo Domingo de Bolonia y su estudio general anexo, convertido desde entonces en un influyente centro de difusión de la observancia, tanto en Italia como en todos los países que enviaban allí sus estudiantes (Fors, "La questione degli studi", p. 480; MorTIER, Histoire, pp. 146-152). La idea de que Salamanca, dado su prestigio como centro de estudios, era el punto clave de una estrategia de conquista, la compartía San Cebrián con Antonio de Nebrija, quien precisamente había comenzado allí su carrera docente a mediados de 1475 y no solo se encontraba en la ciudad cuando el vicario asaltó el convento de los dominicos, sino que apenas una semana más tarde, el 27 de diciembre, obtuvo por oposición su primera cátedra de gramática. Las palabras con que Nebrija se refería unos años después al inicio de su carrera docente pueden parecer algo menos retóricas si las relacionamos con la experiencia de aquellos días: "Para desarraigar la barbarie de nuestra nación no comencé por otra parte sino por el estudio de Salamanca, el cual, como una fortaleza, tomado por combate, no dudaba io que todos los otros pueblos de España vernían luego a se me rendir" (Olmedo, Nebrija, pp. 13 y 23). 
A pesar del fracaso de 1475, esta avenencia tenía cimientos sólidos y prosperó en los años siguientes. Hacia 1470, aunque la reforma vallisoletana había obtenido -con el establecimiento de la Congregación por parte del general Auribelli- el derecho a extenderse al conjunto de Castilla, sus avances territoriales eran todavía muy exiguos. ${ }^{39} \mathrm{Su}$ gran valedor, el cardenal Torquemada, había muerto unos años antes y las perspectivas no eran muy halagüeñas. De hecho, algunos mandatos del maestro general revelan que, para cuando San Cebrián fue nombrado vicario general de la observancia, en las filas de la Congregación se estaba produciendo una crisis vocacional. ${ }^{40} \mathrm{Sin}$ embargo, a partir de 1475, la guerra civil creó las condiciones necesarias para que se cerrara definitivamente la alianza entre los observantes y la monarquía. Nieva llama la atención sobre el hecho significativo de que ningún convento dominico castellano fuera incorporado a la observancia como resultado de la voluntad libremente expresada de sus moradores. La ayuda diplomática, financiera y militar de la Corona fue decisiva en la conquista de la orden por parte de la Congregación, emprendida a partir de estas fechas en contra de la voluntad de la mayor parte de los conventos castellanos. ${ }^{41}$ En contrapartida, el triunfo de la observancia robusteció la sujeción de toda la orden a la autoridad de los reyes, un efecto que no se hubiera deducido necesariamente de un acuerdo con la jerarquía provincial, mucho más robusta y sobre todo sujeta a otros compromisos políticos, tanto foráneos -Roma, es decir, el maestro general y la Santa Sede- como locales, si consideramos el patrocinio que muchos clanes nobiliarios ejercían sobre sus conventos. ${ }^{42}$ La observancia era una opción minoritaria, ideológicamente radical y expeditiva en sus tácticas, pero demasiado débil para imponerse por sus propios medios. En tales circunstancias, la dependencia respecto a sus regios patronos, la identificación con los fines políticos de la monarquía, era completa. La incorporación de los dirigentes de la Congregación a los primeros tribunales de la Inquisición fernandina fue un fruto más de esa alianza.

\footnotetext{
39 Solamente los franciscanos y los jerónimos habían superado, por aquellas fechas, los estadios iniciales de la reforma (GARCíA ORO, "Conventualismo y observancia", p. 270).

40 El día 1 de diciembre de 1474, el general Mansuetis se dirigía a todos los provinciales para, entre otras cosas, advertirles de que los conventos ajenos a la Congregación no debían acoger a frailes observantes, sino devolverlos con sus superiores; y otorgaba particularmente a San Cebrián, nombrado vicario de los observantes castellanos el día anterior, que los frailes de la Congregación podrían ser excomulgados si se trasladaban a conventos ajenos a ella (Mortier, Histoire, pp. 516-517).

41 Nieva, "Reformatio in membris", p. 341; NieVA, "La observancia dominica y la monarquía castellana", p. 520 .

42 Durante el reinado de Juan II (1406-1454), el patronazgo de la monarquía hacia los grandes conventos de la orden de predicadores fue imitado por la nueva nobleza nacida a la sombra de los Trastámara, que a lo largo de la centuria extendió sobre muchos conventos menores una influencia que Isabel y Fernando consideraban contraria a sus intereses (NIEVA, "De la colaboración a la oposición”, pp. 93-96). Sobre las relaciones entre la monarquía y la orden dominicana durante dicho reinado, véase PRIETO, "El acercamiento de la monarquía castellana", pp. 208-215.
} 


\section{De Valladolid a Roma y regreso}

El fiasco de Salamanca obligó a San Cebrián a posponer la conquista de los grandes conventos de la orden. El 27 de junio de 1477, desde Padua, el general Mansuetis le recordaba -ya lo había hecho en noviembre de 1475 con escaso éxito- que no podía reformar ningún convento, y mucho menos el de Salamanca, sin contar con el "mandato expreso" de las autoridades de la orden. ${ }^{43}$ Sin embargo, el poder de sus regios protectores se vio significativamente reforzado tras la batalla de Toro, librada el día 1 de marzo de 1476. La nueva situación política propició avances significativos de la Congregación, que durante los años siguientes aceleró su expansión en detrimento no solo de las autoridades provinciales y de los "conventuales", sino también de otras comunidades observantes que, considerándose tan "reformadas" como pudiera estarlo el convento de San Pablo de Valladolid, no estaban dispuestas a perder la autonomía que se les había reconocido hasta ese momento. ${ }^{44}$

En noviembre de 1477 la Congregación celebró su primer capítulo en su plaza fuerte de Valladolid para pedir a las máximas autoridades de la orden la independencia completa respecto al prior provincial. ${ }^{45}$ Unos meses después, San Cebrián viajó a Italia para trasladar la demanda al capítulo general, cuyas sesiones dieron comienzo en Perugia el 10 de mayo de 1478. Allí, diez días más tarde, Mansuetis le hizo entrega de la carta constitucional de la Congregación de Castilla, con la que el vicario marchó inmediatamente a Roma. El 30 de mayo, atendiendo una petición expresa de los reyes, Sixto IV otorgó dos breves de confirmación, uno dirigido al propio vicario y otro a los obispos de Segovia, Córdoba y Coria, que debían garantizar su puesta en práctica. ${ }^{46}$

\footnotetext{
43 Beltrán, Historia, p. 21.

44 Era el caso de los observantes de Sevilla, cuya autonomía garantizaba el maestro general Mansuetis, con su carta de 18 de marzo de 1475, solamente hasta que Alonso de Carmona dejara de ejercer como vicario general "super fratres et sorores de penitencia commorantes in diocesi Hyspalensi". Después, todos ellos deberían someterse a la autoridad del vicario general de la Congregación (IBIDEM, p. 16). Mortier pensaba que las posteriores reconvenciones hechas por el general a los reformados de la diócesis de Sevilla, en diciembre de 1475 y marzo de 1476, estaban motivadas por la relajación de la observancia regular entre ellos (Mortier, Histoire, pp. 517), aunque parece más razonable pensar que formaban parte de la ofensiva que la Congregación vallisoletana había iniciado para absorberlos.

45 Beltrán, Historia, p. 17.

46 Mortier, Histoire, pp. 517-519; ambos documentos publicados en Bullarium, t. III, pp. 565-567. Sobre el vínculo entre el obispo de Segovia Juan Arias Dávila y el partido isabelino, su participación en la reforma del clero castellano y su influencia en la curia romana, véase AzconA, "Las asambleas del clero de Castilla", pp. 211 y 216; BArrio, "La iglesia de Segovia”, pp. 77-98; RÁBADE, Una elite de poder, pp. 148-167. Por su parte, el dominico Alonso de Burgos, obispo de Córdoba desde 1476, era hijo de hábito del convento de San Pablo de Burgos y se había formado en el de San Pablo de Valladolid, dos de los futuros baluartes de la Congregación. Fue prior de ambos en los años centrales del siglo XV, antes de incorporarse durante la guerra civil al bando del infante Alfonso, de quien fue confesor, y luego al de Isabel, ejerciendo para ella como capellán mayor desde 1473 y como confesor desde 1478 (DíAZ IBÁÑEZ, "Fray Alonso de Burgos", pp. 149-154). Fernando de Toledo, obispo de Coria residente en la curia romana, era un hombre de confianza de Sixto IV, para quien ejerció como datario y legado pontificio; su actuación como protector de la Congregación Dominicana de Castilla fue necesariamente breve, pues murió
} 
San Cebrián todavía permaneció un tiempo en Roma, donde obtuvo algunas concesiones más del pontífice y del maestro general. El mismo 30 de mayo de 1478, Mansuetis prorrogó su mandato trienal, que ya había expirado, hasta el 2 de febrero de 1479, fecha en que la Congregación debía llevar a cabo una nueva elección. ${ }^{47}$ Unos días después llegaron otras concesiones aún más importantes. Como expresión de un aprecio personal que perduraría en los años siguientes, Sixto IV le otorgó el 8 de junio el magisterio en teología. ${ }^{48}$ San Cebrián se convertía de este modo en uno de aquellos magistri bullati que obtenían un título tan codiciado por méritos distintos a los académicos. ${ }^{49}$ Además, entre el 8 y el 10 de junio, en respuesta a la petición de los patronos de los conventos de Caleruega, Benavente y Quejana, el maestro general le otorgó poderes para incorporarlos a la Congregación. ${ }^{50}$ Finalmente, el siguiente día 14, el mismo Sixto IV le confió una delicada misión diplomática: trasladar a la reina Isabel la voluntad del pontífice de que ella y su marido alcanzaran algún tipo de acuerdo con el rey de Portugal para poner fin al conflicto sucesorio. ${ }^{51}$

Estas muestras de afecto del papa y del maestro general de la orden coincidieron con una nueva ofensiva contra Andrés de Toro, que podemos sospechar instigada por el propio vicario. El 5 de junio de 1478 el general Mansuetis remitió al provincial "litterae suae gratiosae absolutionis", es decir, una carta de destitución que debía hacerse pública en el plazo de un mes. Transcurrido este se produciría su cese inmediato y sería sustituido por un vicario provincial, cargo que Mansuetis asignaba de antemano a Pedro de Ocaña, maestro en teología y prior del convento de Toledo, o en su defecto al también maestro Pedro Mariño. Una vez más, el firme apoyo que tenía Andrés de Toro dentro de la orden hizo fracasar la intentona. El capítulo provincial, reunido el 10 de febrero de 1479, lo reeligió con una amplia mayoría de 67 votos contra 11, de manera que Mansuetis no pudo sino confirmarlo en el cargo el 23 de abril siguiente, concediéndole incluso la potestad de acoger en conventos "claustrales" a los frailes que hasta la fecha habían abandonado la observancia, una medida que no podía ser bien recibida por parte de la Congregación. ${ }^{52}$

Es presumible que San Cebrián regresara a Castilla en el verano de 1478 y que, en consecuencia, no estuviera en Roma cuando se promulgó, el día 1 de noviembre, la bula

en febrero de 1479 (Pulgar, Los claros varones, tít. XXIII, pp. 133-135; NiETo SoRIA, Iglesia y génesis del estado moderno, pp. 56-59).

47 Esta orden dejaría en suspenso otra del anterior 22 de mayo que designaba a San Cebrián como vicario y confesor del convento de Santa María de Zamora, el único femenino incorporado por entonces a la Congregación (Beltrán, Historia, p. 18, n. 10 y 11).

48 IBIDEM, p. 18, n. 12.

49 Era una de las "vías alternativas" para acceder a los grados académicos sin cumplir en todo o en parte los requisitos curriculares (GrendLer, The Universities, p. 182). La proliferación de esta práctica se remontaba al papado de Juan XXII, y aunque algunos de sus sucesores intentaron suprimirla, fueron más numerosos los que siguieron recurriendo a ella (Fors, "La questione degli studi", pp. 482-484).

50 El patronato de Caleruega correspondía a la Corona y los otros a los condes de Benavente y a los señores de Ayala, respectivamente (Beltrán, Historia, pp. 18-19).

51 SuÁrez, Politica internacional, vol. I, p. 374.

52 Beltrán, Historia, p. 39. 
Exigit sincerae devotionis, considerada el origen de la Inquisición española. Sin embargo, la proximidad cronológica entre ambos hechos no permite descartar que tomara parte en su negociación. Apoyan el argumento otros indicios, como las misiones diplomáticas que llevó a cabo pocos años después en la curia pontifica, incluida la negociación de asuntos inquisitoriales, y también las características que la representación castellana en Roma tenía antes de 1480, cuando aún se encontraba en manos de oratores eventuales. Como miembro de una orden tan estrechamente vinculada a la Inquisición, y dada su cercanía a los monarcas, estos pudieron aprovechar su presencia en Roma para sumar apoyos a la peculiar demanda de nombrar sus propios inquisidores. ${ }^{53}$

Otro tanto podría decirse de la tramitación de la bula que el 25 de junio de 1478 ordenaba al arzobispo de Toledo, Alonso Carrillo, procesar a Pedro de Osma como sospechoso de herejía. Algunos autores han destacado la relación entre la actividad diplomática de San Cebrián y la causa abierta contra el catedrático de teología de Salamanca a mediados de 1479, un episodio en el que también habría influido la rivalidad entre el convento dominico de Valladolid, cuna de la Congregación, y el de Salamanca, reacio a integrarse en ella. ${ }^{54}$ En cualquier caso, y al contrario que ocurrió con la Inquisición regia, no parece que San Cebrián tuviera mucho interés en involucrarse personalmente en aquel asunto. Formó parte, como su rival Andrés de Toro y varias decenas más de clérigos regulares y seculares, de la lista de expertos que el arzobispo Carrillo llamó el 22 de marzo de 1479 para participar en el juicio; pero ni el vicario ni el provincial acudieron a Alcalá de Henares, quizás porque no era allí donde se libraba el bronco enfrentamiento entre ambas familias dominicanas. ${ }^{55}$ Sí estuvieron presentes algunos frailes que luego ocuparían un lugar destacado en el devenir institucional de la orden y de los primeros tribunales de la Inquisición regia, pero sencillamente porque la convocatoria se extendió a lo más granado de la teología y la canonística universitaria del momento. Desde un punto de vista orgánico, no parece que este proceso ocupe lugar

\footnotetext{
53 Antes de que en 1480 los Reyes Católicos enviaran a Roma al que se considera su primer embajador permanente, Gonzalo de Beteta, siguieron utilizando el sistema tradicional de misiones temporales y, para dar apoyo a estas, recurrieron a los servicios del obispo de Barcelona, Gonzalo Fernández de Heredia, que desde 1475 actuaba en la curia como embajador permanente de Juan II de Aragón. Así, Heredia llegó a ser incorporado como miembro oficial de la misión enviada desde Castilla en 1478, sin duda la que trató -o cuanto menos concluyó- el asunto de la bula inquisitorial (ibidem, p. 172; CABré, "El arzobispo de Tarragona”, p. 303). En el siglo XVII, el cronista dominico Ramírez de Solórzano, deseoso de proclamar la decisiva participación de su convento de filiación, el de San Pablo de Sevilla, en la primerísima aparición del Santo Oficio, llegó a afirmar que su entonces prior, Alonso de Ojeda, no solo había sido el primer inquisidor de la ciudad, sino que en 1478 se había trasladado a Roma con poderes de Torquemada para obtener de Sixto IV la bula fundacional (LARIos, "Los dominicos y la Inquisición”, pp. 105-106). Solo en un punto no estaba desencaminada del todo la fantasiosa e interesada recreación de Solórzano: en 1478 un destacado miembro de la comunidad observante castellana se encontraba en la curia pontificia desempeñando una importante misión diplomática.

54 Innnuzzi, "La condena a Pedro Martínez de Osma”, pp. 29-30.

55 Llama la atención poderosamente que la convocatoria haga referencia al prior provincial de los dominicos y al vicario general de la observancia como "el provinçial de los dominicos claustrales e el provinçial de los dominicos observantes" (LAbajos, Proceso contra Pedro de Osma, p. 98), una expresión que indica hasta qué punto la Congregación había ganado la "batalla del relato".
} 
alguno en la historia de la Inquisición "moderna", como tampoco el otro abierto contra Osma en Zaragoza a finales de 1478. Como bien señala Pablo Pérez, ambos respondían a las fórmulas previas de la Inquisición episcopal, pontificia y dominicana -es decir, "medieval" - que todavía conservaba intacta su capacidad represiva. ${ }^{56}$

Aunque no ha quedado ningún rastro documental, Beltrán de Heredia supone que, tras regresar a Castilla, San Cebrián fue reelegido vicario de la observancia, pues continuó ejerciendo el cargo durante los años siguientes. Sus esfuerzos por incorporar a la Congregación el mayor número de conventos se redoblaron. En 1479 recorrió el país "de extremo a extremo" para reformar, por mandato de los reyes, los conventos de San Pablo de Córdoba, Santo Domingo de Jerez y Santo Domingo de La Coruña. el 7 de junio de 1479, el general Mansuetis confirmó conjuntamente estas actuaciones en Roma, al mismo tiempo que le instaba a emprender cuanto antes la reforma de Caleruega, a la que había accedido por petición expresa de la reina Isabel y que temía no se hubiera llevado aún a cabo. En torno al verano le llegó el turno al convento de Santa María de la Peña de Francia, en la diócesis de Salamanca, donde San Cebrián contó con la ayuda de otro ferviente reformista, Pedro Cavaco, prior del convento de Piedrahita, que debía aportar los frailes necesarios para sustituir a los "claustrales" expulsados. En una declaración fechada el 13 de marzo de 1480, el maestro general admitía que la reforma de la Peña de Francia se había hecho "por mandato" de la reina Isabel y excluía el cenobio de la jurisdicción del provincial, a quien amenazaba con destituir y excomulgar si se oponía. ${ }^{57}$ Por último, en el mismo mes de marzo, la Congregación se hizo con uno de los conventos mayores de la orden, el de San Pedro Mártir de Toledo, a resultas de otra oportuna mediación de los monarcas ante el general. ${ }^{58} \mathrm{Al}$ parecer, Mansuetis expresó algunos reparos en esta ocasión, pero el vicario contaba con la inestimable complicidad del prior Juan de Yarza, protagonista luego de una destacada carrera dentro de la orden dominicana y de la Inquisición. ${ }^{59}$

Sabemos poco acerca de los procedimientos utilizados en aquella "campaña de conquista" de 1479-1480, aunque resulta significativo que la orden del general Mansuetis para reformar Toledo otorgara al vicario "plena potestate et praeceptis et censuris quod nullus impediat”. Sabemos hasta dónde llegaban tales poderes gracias a la carta con la que Mansuetis le instaba a emprender la reforma del convento femenino de Caleruega, una de las pocas cuyo texto original se ha conservado. El maestro general estaba mo-

\footnotetext{
56 PÉrez GARCÍA, "La Inquisición y el libro", pp. 79-80; la argumentación apunta al problema, todavía sin resolver, de si Fernando e Isabel fomentaron -o pretendieron fomentar- las actuaciones de aquella vieja inquisición antes de contar con la nueva, y de las diferencias que en este sentido pudieron producirse, no solo entre ambas coronas, sino también entre unos territorios y otros dentro de cada una de ellas.

57 Beltrán, Historia, pp. 18-20, n. 17; Nieva, "Reformatio in membris", pp. 325-326, n. 84.

58 Beltrán, Historia, p. 19.

59 Yarza fue en 1483 uno de los primeros inquisidores de Jaén y se convertiría en vicario general de la observancia en 1489 (Lorente, San Pedro Mártir el Real, p. 64). Mansuetis puso objeciones a una actuación que consideraba innecesaria a causa del "óptimo nivel de vida religiosa" que caracterizaba el convento de Toledo (NIEvA, "La observancia dominica y la monarquía castellana”, pp. 521-522), pero resulta obvio que a esas alturas la reforma observante no trataba ya de eso.
} 
lesto porque, transcurrido un año desde que firmara la licencia correspondiente, San Cebrián no la había hecho efectiva y defraudaba así una petición expresa de la reina Isabel. Mansuetis se preguntaba por los motivos del retraso pero, aunque llegaba a poner en duda la competencia del vicario, no ignoraba la posibilidad de que se hubieran producido resistencias:

"Me admira y asombra muchísimo que dicha reforma no se haya hecho hasta ahora, sea por vuestra negligencia, por rebelión, resistencia u oposición de las monjas, o por cualquier otra causa."60

La carta ponía remedio a semejante eventualidad. La priora y las monjas de Caleruega debían obedecer al vicario como si del propio maestro general se tratara, aceptando la reforma sin contradicción alguna "in virtute Spiritus Sancti et sanctae obedientiae" y bajo pena de excomunión; la misma en que incurrirían el provincial y otros miembros de la orden si se opusieran, perdiendo por añadidura sus cargos.

No sabemos qué sucedió realmente en todos estos conventos cuando San Cebrián y los suyos acudieron a reformarlos. Solo encontramos algunas indicaciones relativas a la Peña de Francia, donde San Cebrián procedió de forma similar a como lo había hecho en Salamanca unos años antes. Junto a Pedro Cavaco y un grupo formado por frailes "de observantia reformatorum nuncupatorum" y otros "clérigos y laicos", ocupó el convento por la fuerza y procedió a depurarlo de elementos desafectos, purga de la que dejó constancia el procedimiento abierto más adelante en la curia pontificia para exculpar a los agresores. Al contrario que en Salamanca, esta vez no acudió el pueblo en armas en defensa del cenobio, seguramente porque se encontraba en un paraje poco poblado y lejos de cualquier ciudad, aunque sí regresaron poco después los "claustrales" expulsados, en compañía de algunos laicos, para recuperar el convento por la fuerza o saquear al menos sus riquezas. ${ }^{61}$

Por su parte, el provincial Andrés de Toro prefirió articular una respuesta más ajustada a derecho. Junto con cierto Velasco de Medina del Campo, representante de la diócesis salmantina, se apresuraron a lanzar sus admoniciones contra San Cebrián y sus cómplices, a quienes declararon excomulgados. Adujeron para hacerlo un mandato de Sixto IV, fechado el 1 de mayo de 1472, que aplicaba dicha pena a los frailes "llamados observantes", miembros de cualquiera de las órdenes mendicantes, que pretendieran reformar los conventos sin licencia expresa del maestro general o del prior provincial,

60 La carta está fechada en Roma el 7 de junio de 1479, se conserva en el AHN y fue publicada en su día por Beltrán, Historia, pp. 233-234; la traducción es nuestra. En un ejercicio de pragmatismo administrativo, Mansuetis contemplaba en un post scriptum la posibilidad de que, después de todo, San Cebrián sí hubiera llevado a cabo la reforma de Caleruega, de manera que esta misma carta serviría para aprobarla oficialmente.

61 En septiembre de 1479 los monarcas cursaban orden a los oficiales de la región para perseguir a los asaltantes, recuperar las joyas y ornamentos robados e imponerles un severo castigo por la destrucción causada (NIEVA, "Reformatio in membris", pp. 322 y 325-326, n. 74). 
prohibiéndoles expresamente expulsar "con injurias y agresiones a los frailes llamados conventuales" para substituirlos por otros ajenos a la comunidad. ${ }^{62}$ Para responder a esta amenaza, el vicario tomó de nuevo el camino de Roma. Esta vez viajaría, de forma oficial, como embajador de los reyes de Castilla.

\section{Dos misiones diplomáticas y un conflicto bélico}

Según Suárez Fernández, entre 1480 y 1482, el vicario San Cebrián acudió en dos ocasiones a Roma para tratar con Sixto IV, en nombre de los Reyes Católicos, algunos asuntos de política eclesiástica. La primera de esas misiones diplomáticas habría consistido en negociar la concesión de la décima destinada a financiar una flota contra los turcos y apaciguar el conflicto surgido en torno a la provisión de varios obispados, particularmente el de Cuenca. ${ }^{63}$ Suárez sitúa a San Cebrián en Roma -a donde habría ido en compañía del embajador Gonzalo de Beteta- en julio de 1480, pero en realidad se encontraba allí desde unos meses antes. El 22 de abril, los registros del maestro general de los dominicos incluyeron ciertas "ordenaciones" firmadas en Roma por el vicario de la observancia y el prior provincial Andrés de Toro. Beltrán considera que se trataba de un acuerdo de "convivencia" que ambas partes habrían alcanzado con la mediación de Mansuetis, pero no tenemos más detalles al respecto. Podemos suponer que fray Andrés acudió personalmente a Roma para presentar sus quejas contra "el proceder a veces un tanto violento de San Cebrián” y que coincidió allí con él, o bien que el general los convocó a ambos para evitar un mayor enconamiento del conflicto. ${ }^{64}$ En cualquier caso, apenas dos meses después, el vicario obtuvo de Sixto IV una bula que le dejaba las manos completamente libres y restaba mucha utilidad al anterior acuerdo, que San Cebrián pudo haber suscrito con la única intención de ganar tiempo. La muerte de Leonardo Mansuetis el siguiente 26 de julio acabaría por convertirlo en papel mojado. ${ }^{65}$ La bula Sedis Apostolicae circunspecta, fechada el 13 de junio de $1480,{ }^{66}$ reconocía los graves hechos ocurridos en la Peña de Francia, que Andrés de Toro y las autoridades diocesanas salmantinas habían denunciado, pero también daba por buenos los argumentos de la defensa, que eran fundamentalmente dos. El primero, que San Cebrián y los suyos no habían pretendido ofender a nadie y que si reformaban los conventos lo hacían por el bien de la orden y de la religión cristiana. El segundo, más prosaico pero de mucho mayor peso político, que los reyes de Castilla habían suplicado la absolución del vicario a cuenta de la devoción que sentían por la observancia. El papa cedió sin demora a tales demandas y no solamente exoneró a San Cebrián y sus cómplices (mediante el

\footnotetext{
62 El texto completo de este documento se incluyó, junto con el relato de lo sucedido en la Peña de Francia, en la bula de exculpación de San Cebrián, a la que nos referiremos luego (Bullarium, t. III, pp. 588-590).

63 SuÁrez, Política internacional, vol. I, pp. 255-256.

64 Beltrán, Historia, p. 25, n. 28.

65 Mortier, Histoire, p. 540.

66 Bullarium, t. III, pp. 588-590.
} 
usual procedimiento de que un confesor elegido por el interesado le absolviera de sus faltas), sino que otorgó al vicario y a sus sucesores la capacidad de reformar conventos "iuxta conscienciam suam", de manera que ni ellos ni quienes les ayudaran, clérigos o laicos, incurrieran en las penas establecidas por el mandato papal de 1472, de cuyo cumplimiento quedaban especialmente eximidos los dominicos castellanos. Sixto IV no solo justificaba los pasados actos del vicario, sino también los futuros. ${ }^{67}$

No sabemos cuándo regresó el vicario San Cebrián a Castilla, pero es posible que no lo hiciera antes de marzo de 1481, momento en que obtuvo de Sixto IV otras dos importantes concesiones. El día 4 de dicho mes, un motu proprio del papa le otorgó el poder de conferir grados académicos con los mismos efectos que un estudio general. De esta manera, la Congregación podría paliar el obstáculo que para las carreras escolares de sus miembros suponía no haber podido hacerse con el convento de Salamanca, principal centro educativo de la Provincia Dominicana de España. ${ }^{68}$ El 14 de marzo, como resultado de una negociación que debió implicar necesariamente al maestro general de la orden y al vicario de la Congregación de Lombardía, el papa ordenaba a este último -a instancias de un demandante anónimo que es difícil no identificar con San Cebriánque enviara de regreso a su país a los frailes observantes españoles que residían en los conventos reformados de Italia. La poca disposición de los "conventuales" a aceptar la observancia, agravada con la deserción de algunos que en un primer momento la habían abrazado, ponía en peligro los progresos de la Congregación, pues sus efectivos no bastaban para repoblar los conventos que iban siendo incorporados en número creciente. La solución adoptada por el vicario San Cebrián, traer observantes desde Italia, la había ensayado tres décadas antes el cardenal Torquemada para afianzar la reforma en el convento de San Pablo de Valladolid. ${ }^{69}$

El 14 de junio de 1481 una carta real sitúa a San Cebrián en Zaragoza. El monarca daba cuenta de que con anterioridad le había confiado una misión en Roma cuyos resultados no le satisfacían plenamente, pues las condiciones en que el papa había concedido la décima de cruzada no eran las deseadas. ${ }^{70}$ Para remediarlo se estaban haciendo nuevos preparativos diplomáticos. El día 28 de junio la reina Isabel ordenó a Gabriel Sánchez, por entonces tesorero del príncipe Juan, que entregara al vicario 7.200 sueldos jaqueses para cubrir los gastos de su viaje de regreso a Roma. ${ }^{71}$ En julio la cancillería redactó

67 Estas iniciativas legales ex post facto se habían utilizado antes para ratificar los asaltos de conventos llevados a cabo anteriormente por los observantes franciscanos. Como la de Sixto IV en 1472, también las prohibiciones lanzadas entonces por Nicolás V y Calixto III terminaron cayendo en saco roto (GARCíA Oro, "Conventualismo y observancia", pp. 257-261).

68 Beltrán, "Los comienzos”, pp. 415 y 425.

${ }^{69}$ Bullarium, t. III, p. 597. Beltrán de Heredia señala la resistencia de los frailes más jóvenes a integrarse en los conventos reformados e incluye la llegada de efectivos humanos desde Italia entre las causas que justifican la semejanza entre las congregaciones de Lombardía y Castilla (Beltrán, Historia, 26-27).

70 SuÁrez, Politica internacional, vol. I, p. 256, n. 60.

71 Según la credencial dirigida por la reina a los auditores del tesorero (Torre, Documentos, p. 161; ACA RC 3615, f. 71). Se trata de una suma más que respetable, pero la ambigüedad del documento hace difícil saber si incluía los gastos ya realizados por San Cebrián en su anterior viaje o tan solo los que debía realizar en el próximo. 
unas prolijas instrucciones que San Cebrián, a quien se daba el tratamiento de confesor de los reyes, habría de llevar consigo para compartirlas con el embajador Beteta. Ambos debían, entre otras cosas, cerrar la crisis de los obispados, asegurando que la Corona entregaría Salamanca al cardenal Riario, sobrino del papa, y Cartagena al vicecanciller Borja, si a cambio se le garantizara la provisión de Tarazona y Cuenca. También señalarían al pontífice algunos cambios en la concesión del subsidio de cruzada, incluyendo que no enviara ningún legado, nuncio o colector extranjero a Castilla con poderes para recaudar dicho subsidio o las rentas y expolios de los obispados vacantes, proponiendo que tales funciones fueran delegadas en el vicario San Cebrián. ${ }^{72}$

Al parecer, el regreso de Alonso de San Cebrián a Roma complació a Sixto IV, que el 21 de agosto de 1481 confirmó la absolución que el vicario, actuando como procurador suyo, había otorgado unos meses antes a Isabel y Fernando por encarcelar en 1479 al nuncio Francisco Ortiz, un canónigo de Toledo que había recibido del papa el difícil encargo de tomar posesión del obispado de Cuenca en nombre del cardenal Riario, y que también era sospechoso de apoyar al rey de Portugal en el conflicto sucesorio. ${ }^{73}$ Una semana después, el 29 de agosto, el papa informaba a los reyes de que había recibido en audiencia a San Cebrián, quien le había transmitido la "devoción y reverencia" de sus patronos. Sixto IV se declaraba satisfecho y les exhortaba a perseverar en aquella actitud, asegurando que recibirían de él toda la ayuda que pudiera darles. Al final de la misiva dedicaba unas líneas a ensalzar las virtudes del vicario, a quien "de manera espontánea y sin mediar solicitud previa” recomendaba para algún obispado vacante, pues estaba convencido de que era merecedor de tal dignidad "pro sua probitate et vite integritate" y animaba a los reyes a escribirle para tratar directamente el asunto. ${ }^{74}$ En términos más generales, el éxito de Beteta y San Cebrián en las negociaciones que les habían sido encomendadas, propició que el papa enviara un representante a la corte regia con la misión de poner por escrito los acuerdos que ambos embajadores habían alcanzado en Roma. E1 29 de diciembre de 1481 fueron expedidas las credenciales de Domenego Centurione, un mercader genovés asentado en Sevilla que actuaba desde 1474 como depositario de la Cámara Apostólica. ${ }^{75}$ Sin embargo, en el momento en que parecía consolidarse una substancial mejora de las relaciones con la Santa Sede, enrarecidas por el conflicto de los obispados, las complejas circunstancias de la política italiana levantaron nuevas tormentas.

\footnotetext{
72 Si el papa insistía en designar un colector distinto, los embajadores vetarían a Francisco Ortiz, implicado en el conflicto del obispado de Cuenca, y exigirían que el enviado no ostentara en ningún caso poderes de legado o nuncio (SuÁrez, Política internacional, vol. I, pp. 494-499).

73 IBIDEM, pp. 247-249. Podemos suponer que San Cebrián había absuelto a los reyes tras regresar a Castilla de su anterior viaje a Roma, y quizás por ese motivo se le calificaba como confesor regio en las instrucciones de julio de 1481. De vuelta en la Santa Sede, y para obtener la necesaria confirmación, el vicario informó al pontífice de que los reyes habían liberado a Ortiz y revocado las demás medidas tomadas "in preiudicium libertatis ecclesiastice" (ibidem, pp. 499-500).

74 IBIDEM, pp. 500-501.

75 IBIDEM, pp. 503-504. Sobre los orígenes y actividades comerciales de Centurione, antes y después de su nunciatura, ENSENYAT DE VillalongA, "La noble, acaudalada y poderosa familia”, pp. 598-603.
} 
Suárez y Azcona dan poco o ningún crédito al relato que Hernando del Pulgar hizo del primer encuentro entre Centurione y los monarcas, que se habría producido en Medina del Campo entre febrero y marzo de $1482 .{ }^{76}$ Según el cronista, Fernando e Isabel se quejaron amargamente de los continuos agravios que les hacía el papa y se negaron a recibir a Centurione ni a ningún otro nuncio, amagando con expulsarlo inmediatamente de sus reinos. Sin embargo, las aguas volvieron a su cauce "después de algunos días" merced a los buenos oficios del cardenal Mendoza, que convenció a los monarcas de que "tornasen a fablar en la concordia con el papa". ${ }^{77}$ Sin duda, el cronista pudo cargar las tintas para dar mayor efecto dramático a su narración, pero cabe considerar que, en aquellos precisos momentos, las relaciones con Roma estaban sufriendo un rápido $\mathrm{y}$ agudo deterioro que tal vez explique mejor la acritud con que fue recibido el inoportuno Centurione.

A finales de 1481 Venecia y Ferrara se encontraban al borde de la confrontación como resultado de un progresivo deterioro de las relaciones entre ambos estados que se remontaba a la llamada guerra de los Pazzi (1478-1479), que el ataque otomano al reino de Nápoles en 1480 había cerrado en falso, forzando una precaria unidad. En noviembre de 1481, ante el incremento de la presencia militar veneciana en la frontera ferraresa, el duque Ercole d'Este buscó la mediación del papa. ${ }^{78}$ Sin embargo, Sixto IV tenía otros planes. En enero de 1482 había cerrado una alianza con la Serenísima que debió negociarse durante los meses anteriores. También el duque de Ferrara contaba con aliados: Milán y Florencia, pero sobre todo Nápoles, donde reinaba su yerno Ferrante, que era a su vez primo y cuñado de Fernando de Aragón. Para este, la alianza entre ambas ramas familiares constituía el núcleo mismo de su política italiana, siempre orientada a mantener un status quo que evitara la invasión francesa de la península. ${ }^{79}$ La escalada diplomática se prolongó hasta el inicio de las hostilidades en mayo de 1482, coincidiendo con un grave enfrentamiento entre el papa y el rey Fernando a cuenta de la naciente Inquisición española, que estalló el 29 de enero de 1482 con el breve Nunquam dubitabimus y alcanzó su peor momento con la bula Gregis dominici, promulgada el siguiente 18 de abril. ${ }^{80}$ Sixto IV puso en cuestión los medios utilizados por la diplomacia hispana para conseguir la bula fundacional de 1478, condenó la brutal actuación de los tribunales en Sevilla y Valencia, y amenazó con destituir a los inquisidores que los reyes habían nombrado. Fernando, en una reacción tan colérica como jurídicamente inapropiada, terminó exigiendo al papa que no se entrometiera en la persecución de la herejía, de la que se consideraba único garante. ${ }^{81}$

\footnotetext{
76 SuÁrez, Política internacional, vol. I, p. 257. Los reyes llegaron a Medina del Campo el 3 de febrero, procedentes de Valencia, y Fernando partió hacia Andalucía el 14 de marzo, permaneciendo la reina unos diez días más antes de emprender viaje a Córdoba (Romeu de Armas, Itinerario, pp. 100-102).

77 Pulgar, Crónica, pp. 178-179.

78 Guerra, Soggetti a "ribalda fortuna", pp. 95-99.

79 Calmette, "La politique espagnole dans la guerre de Ferrare", p. 227.

80 Cruselles, "Fernando el Católico, la familia Borja y la nueva Inquisición”, pp. 35-39.

81 Un análisis detallado del conflicto en Sesma, Fernando II y la Inquisición, pp. 41-59.
} 
Si como parece, Domenego Centurione llegó a Medina del Campo en fechas inmediatamente posteriores a la promulgación del breve pontificio del 29 de enero, la tensión estaba justificada. Con todo, este tipo de manifestaciones de hostilidad no dejaban de ser una baza más en el juego diplomático, y de la misma manera que los reyes no llegaron a expulsar a Centurione para evitar lanzar por la borda varios años de negociaciones sobre los obispados en disputa y la bula de cruzada, ${ }^{82}$ tampoco sus embajadores en Roma renunciaron sin más al terreno ganado desde 1478 en el asunto de la Inquisición.

Pese a su gravedad, los conflictos diplomáticos internacionales no hicieron que San Cebrián olvidara los suyos propios. En el momento en que mayor era su cercanía a los reyes y al papa, tuvo lugar un nuevo y definitivo intento de acabar con Andrés de Toro, caído en desgracia tanto en Castilla como en Roma. El 29 de diciembre de 1481, el provincial fue destituido por el nuevo maestro general de los dominicos, Salvo Cassetta, que decía actuar a instancias de los monarcas y de una parte de la orden. A continuación fue nombrado vicario de la Provincia de España el prior del convento de San Esteban de Salamanca, Juan del Espíritu Santo. ${ }^{83}$ Pero el 12 de febrero de 1482, en un aparente juego de despropósitos que Beltrán de Heredia no duda en tildar de cómico, Cassetta dio marcha atrás alegando que los reyes se habían retractado; por último, el siguiente 3 de mayo, revalidó la destitución de manera definitiva. ${ }^{84}$ La transición se prolongó durante más de un año, indicio evidente de la confusión que reinaba en la orden. El maestro general temía que quienes se oponían a la Congregación prolongaran el enfrentamiento, y ya el 31 de mayo de 1482, apenas transcurridas unas semanas desde que Andrés de Toro fuera cesado, exigía que el capítulo provincial designara un sucesor "adecuado" para que la observancia pudiera extenderse a toda la Provincia. Hasta el verano de 1483 no se produjo la elección del nuevo prior provincial, Bernardo de Santa María, que fue ratificado en Roma el 10 de septiembre. Sin embargo, su mandato fue tan breve que quizás no llegó siquiera a tomar posesión del cargo, que durante los tres años siguientes fue ejercido por el mencionado prior salmantino, Juan del Espíritu Santo. ${ }^{85}$

\footnotetext{
82 Con unos meses de retraso, el acuerdo fue suscrito el día 3 de junio de 1482, antes incluso de que el conflicto de Ferrara alcanzara su punto álgido (SuÁrez, Política internacional, vol. I, pp. 257-258).

83 Beltrán, Historia, pp. 39-40, n. 5. La identidad del vicario provincial propuesto expresa la soledad en que se encontraba Andrés de Toro, pues hasta el prestigioso cenobio salmantino, en el que él mismo había profesado, colaboraba en la maniobra.

84 La carta del 12 de febrero anulaba el primer cese "quia inventum est non fuisse de mentis regis Hispaniae quod absolveretur". Quizás los monarcas temieron las consecuencias de intervenir tan abiertamente en la orden, pero al final valoraron más las ventajas y volvieron a rectificar, dejando en una posición un tanto ridícula a Cassetta, que para excusarse alegaba supuestos malentendidos: "et fuerunt revocatae litterae secundae (...) et de novo est absolutus. Haec autem mutatio fuit facta quia nunquam nisi modo fuit facta clara et plena informatio de voluntatis regis Hispaniae" (IBIDEM, p. 40).
}

85 IBIDEM, pp. 40-41, n. 6. 


\section{Ocho inquisidores para los reinos de Castilla y León}

El segundo mandato de Alonso de San Cebrián al frente de la Congregación de la Observancia expiraba a principios de 1482. Dado que el nombramiento de Centurione en diciembre de 1481 había puesto fin prácticamente a la misión del vicario en Roma, es probable que tuviera previsto regresar a Castilla para conseguir la reelección o, al menos, presidir el capítulo electivo. Sin embargo, el 28 de enero el general Cassetta lo confirmó sine die en el ejercicio de su cargo, aduciendo que no podía regresar a su país porque los reyes requerían de sus servicios en Roma. ${ }^{86}$ Quince días más tarde fue promulgada la bula de los ocho inquisidores, de manera que es fácil suponer qué negocios lo retenían en la curia. De hecho, en el breve Nunquam dubitabimus de 29 de enero de 1482, se afirma que un embajador (orator) de los reyes había informado oportunamente al papa sobre la honradez y rectitud de los inquisidores de Sevilla, recomendación que les valió no ser destituidos por el papa -en contra de la opinión de algunos cardenalesy evitó que la censura se extendiera sobre los reyes como responsables últimos de su nombramiento, lo que en términos diplomáticos hubiera sido llevar las cosas demasiado lejos. ${ }^{87}$ La prolongación de la estancia de San Cebrián en Roma, el aprecio que el papa le había demostrado previamente y su posterior intervención en la bula de los ocho inquisidores, arrojan luz sobre la identidad de dicho embajador. Dado que el problema afectaba a los dominicos, nadie mejor que un dominico para intentar salvar los muebles. Habitualmente, la bula Apostolice sedis providentia, fechada el 11 de febrero de 1482, ha sido entendida como un paso adelante en la consolidación institucional de la Inquisición española, pues preparaba el ascenso de Tomás de Torquemada al cargo de inquisidor general de Castilla. ${ }^{8}$ Es verdad que el hecho de que se trate de un nombramiento colectivo -nada menos que de ocho inquisidores- ha causado inquietud en muchos estudiosos e incluso algunos siguen esperando que aparezca el verdadero nombramiento de Torquemada. En realidad, la bula en cuestión fue más bien un paño caliente, un parche que Alonso de San Cebrián consiguió poner in extremis en la línea de flotación de la política inquisitorial de la monarquía para taponar la vía de agua abierta por el breve pontificio del 29 de enero anterior.

Breve y bula guardaban entre sí una relación funcional que resulta patente en sus respectivos preámbulos. En ambos documentos el papa expresaba su intención de dar respuesta a las "múltiples lamentaciones" provocadas por los inquisidores que Fernando e Isabel habían

\footnotetext{
86 “(...) et talis confirmatio est facta quia ipse non potest nunc patriam ire, cum sit occupatus pro negotiis regis hic in curia" (IBIDEM, p. 25, n. 29).

87 “(...) no obstante, para que no parezcamos reprobar a los tales Miguel [Morillo] y Juan [de San Martín] como menos idóneos, inhábiles e insuficientes, y por lo tanto condenar su nombramiento realizado por vosotros [los reyes de Castilla], dando por buena la información que acerca de la probidad e integridad de los tales Miguel y Juan nos fue facilitada por vuestro representante en nombre vuestro, queremos que los tales Miguel y Juan sigan como Inquisidores" (MARTínez DíEz, Bulario, p. 91; la cursiva es nuestra). ${ }^{8}$ IBIDEM, pp. 92-95. Con alguna excepción como Herrero del Collado ("El proceso inquisitorial", pp. 680-681), quien interpretaba los efectos de la bula como una verdadera anulación de las prerrogativas que en 1478 habían conseguido los reyes en materia inquisitorial.
} 
nombrado en Sevilla en virtud de "ciertas cartas" que el propio Sixto IV les había otorgado (la bula fundacional de 1478), pero cuyos términos habían sido presentados al pontífice para su aprobación sin la necesaria claridad -“confusamente"-y luego se habían revelado contrarios "a los decretos de los Santos Padres, de nuestros predecesores y de la observancia común". En consecuencia, continuaba la bula de febrero, el papa dispuso "por otras letras nuestras" - es decir, el breve de enero- ${ }^{89}$ que el oficio inquisitorial volviera a ejercerse en los reinos de Castilla y León "de acuerdo con lo dispuesto en el derecho". Los inquisidores estaban obligados a acordar sus actuaciones con los obispos y los reyes se limitarían a prestarles auxilio en "las cosas que a ellos les competían". En términos jurídicos, esto suponía devolver las competencias de todos ellos al estado anterior a 1478. La bula Exigit sincerae devotionis no fue derogada expresamente ni fueron destituidos los inquisidores cuyos nombramientos había propiciado, pero era fácil suponer que Sixto IV no aceptaría más designaciones directas por parte de los reyes. De hecho, nunca se produjo otra.

Sin embargo, lo que motivó de manera específica la bula de febrero de 1482, que no iba dirigida a los monarcas sino a los ocho nuevos inquisidores, fue una advertencia de la diplomacia hispánica respecto a los reinos de Castilla y León, demasiado extensos para que los inquisidores entonces disponibles -los miembros del denostado tribunal de Sevilla- pudieran hacer frente "ellos solos" a la herejía. De manera que el pontífice, recurriendo a "la fiel información" que le había proporcionado el vicario San Cebrián, embajador de los reyes ante la Santa Sede, accedió a nombrar otros ocho inquisidores para que actuaran en dichos reinos "guardando el contenido y el tenor de nuestras últimas letras", es decir, respetando las limitaciones establecidas en el anterior breve de enero. La nómina, integrada por prominentes miembros de la orden de predicadores, fue ordenada según la jerarquía de los grados académicos. Así, a la cabeza de un primer grupo de cinco maestros en teología, encontramos a Pedro de Ocaña, catedrático en Salamanca, hijo de hábito del convento de San Pedro Mártir de Toledo, del que había sido prior en $1473 .{ }^{90}$ La identificación del segundo nombre resulta problemática, ${ }^{91}$ aunque en nuestra

\footnotetext{
89 Existe un desfase cronológico de dos días entre la fecha del breve ("xxix ianuarii") y la fecha que se le atribuye en la bula ("pridie kalendas februarias") que en principio cabe atribuir a un error en la confección de esta última.

90 Serrano, Toledo y los dominicos, p. 258. Hay constancia de su presencia entre 1460 y 1477 en dicho convento (IBIDEM, p. 298), de cuyo estudio habría sido regente, a decir del cronista dominico Ramírez de Solórzano (LARIos, "Los dominicos y la Inquisición", p. 107). Una vez en Salamanca se incorporó al convento de San Esteban y destacó como opositor al tomismo de Pedro de Osma, en cuyo proceso participó como calificador en 1479 (Fuertes, "Contra el nominalismo", p. 252; Labajos, Proceso contra Pedro de Osma, pp. 57 y 117). Fue uno de los candidatos a ocupar el cargo de vicario de la Provincia de España cuando el maestro general de la orden depuso al provincial Andrés de Toro en 1478 (véase $\mathrm{n}$. 52). De hecho, hasta cuatro de los dominicos "conventuales" que Alonso de San Cebrián incluyó en esta bula, estuvieron implicados en las maniobras contra Andrés de Toro en calidad de vicarios provinciales en potencia o de inmediatos sucesores suyos en el cargo de prior provincial. El mencionado Ocaña y Pedro Mariño tomaron parte en el intento fallido de 1478; Juan del Espíritu Santo y Bernardo de Santa María en el de 1481-1482, que se puso en marcha mientras se tramitada dicha bula en la curia pontificia, aunque culminó unos meses después de su promulgación (véanse n. 83 y 85).

91 El desacuerdo respecto a su identidad entre los historiadores clásicos de la Inquisición española se ha transmitido a los estudios modernos, que resultan inútiles en este punto. Páramo (De origine, p. 136) lo
} 
opinión se trata de Pedro Mariño, profeso de San Esteban de Salamanca, que en 1476 era prior del convento de Vivero ${ }^{92}$ y más tarde sería prior provincial. ${ }^{93}$ Tras Alonso de San Cebrián, que como hemos visto había conseguido su magisterio cuatro años antes en los despachos del Vaticano, aparecen otros dos hijos de hábito del convento de Salamanca, también catedráticos de teología en esa universidad: Juan de Santo Domingo ${ }^{94}$ y Juan del Espíritu Santo. ${ }^{95}$ Completan la lista tres teólogos con títulos menos solemnes. Entre ellos, un licenciado llamado "Rodericus de Searra" ocupa el sexto lugar. Los historiadores de la orden dominicana y de la Inquisición han preferido interpretar este apellido como Segarra, sin dar más explicaciones al respecto. ${ }^{96}$ El séptimo es para el

llamó "Petrum Martinum", pero algunos cronistas dominicos del siglo XVII prefirieron llamarle Pedro Martínez, como hacen Ramírez de Solórzano (Larios, "Los dominicos y la Inquisición", p. 107) y Juan de Araya (Cuervo, Historiadores, vol. I, p. 506). Llorente (Memoria histórica, p. 67), citando cierta compilación de breves pontificios compuesta en 1566 y de la que decía tener copia, lo llamó Pedro Murillo; Fita ("Nuevas fuentes", p. 462) transcribe "Petro Martino", al igual que LlorCa (Bulario pontificio, p. 64); sin embargo, PinTA Llorente (La Inquisición española, p. 37), aunque cita el trabajo del padre Fita, se inclina por Pedro Morillo. En el documento original (AHN, Códices, libro 1, f. 20) se observa cierta vacilación gráfica, pero hemos de inclinarnos por la forma "Petro Marino", como ha hecho MArtínez DíEz (Bulario, pp. 92-93) en la versión latina de su edición bilingüe, aunque en la correspondiente traducción castellana opte de forma inopinada por Pedro Martín.

92 Según el acta notarial levantada tras el asalto perpetrado contra dicho convento de San Esteban por el vicario San Cebrián (Cuervo, Historiadores, vol. II, pp. 489-490).

93 Durante un corto periodo de tiempo entre 1487 y 1488 (Beltrán, Historia, pp. 41-42). Ya había sido propuesto en 1478 como candidato a la vicaría de la Provincia, junto a Pedro de Ocaña, tras una de las destituciones fallidas del provincial Andrés de Toro (IBIDEM, p. 39).

94 Cuervo, Historiadores, vol. I, pp. 315-316. Alabado como matemático por el cronista Olmeda, y como teólogo y predicador por Marineo Sículo (Beltrán, "Nebrija y los teólogos de San Esteban", p. 449), había participado también en el proceso de Alcalá de 1479 (Labajos, Proceso contra Pedro de Osma, pp. 99 y 131) y entre 1497 y 1507 ocupó la cátedra salmantina que había sido antes del maestro Osma (FuERTES, "La estructura de los saberes", p. 142).

95 Era uno de los frailes que moraban en San Esteban cuando el convento fue asaltado por el vicario San Cebrián y sus secuaces en 1475 (Cuervo, Historiadores, vol. I, p. 489). En el proceso contra Pedro de Osma formó parte, junto con Diego Deza y algunos otros, de un pequeño grupo de defensores del maestro que llegó a ser acusado de complicidad con él (Labajos, Proceso contra Pedro de Osma, pp. 61, 67 y 69). En mayo de 1482 fue nombrado vicario de la Provincia de España tras la destitución de Andrés de Toro. Fue prior provincial entre 1483 y 1486 (BELTRÁn, Historia, pp. 40-42). En 1488, tras la incorporación a la observancia del convento de San Esteban de Salamanca, llegó a ocupar de manera interina el vicariato de la Congregación (IBIDEM, p. 55). En 1491, siendo catedrático de hebreo, intervino junto con otros docentes salmantinos en el proceso del niño de La Guardia (FitA, "La verdad sobre el martirio del Santo Niño de la Guardia", pp. 6971). En 1495 estuvo al frente del estudio general del convento de San Esteban. Ya había muerto cuando, en torno a 1515, el ínclito Nebrija hizo de él objeto de chanza en su correspondencia, junto con otros antiguos colegas salmantinos. Mejor opinión tenía de él otro contemporáneo, Lucio Marineo Sículo, quien llegó a ensalzar sus dotes de predicador (Beltrán, "Nebrija y los teólogos de San Esteban”, pp. 447-450).

96 Ignorando otras formas posibles, como Seara. Segarra es la forma preferida por los escritores antiguos, como el influyente Páramo (De origine, p. 136), aunque el sevillano Solórzano lo llamaba Rodrigo Segura y decía sospechar que había profesado en el convento de San Pablo de Sevilla, objeto precisamente de su crónica (LARIOS, "Los dominicos y la Inquisición”, p. 107); pero la principal influencia sobre los historiadores modernos la han ejercido LloRCA (Bulario, p. 64), que cita el documento original del AHN aunque transcribe "Segarra", FITA ("Nuevas fuentes", p. 462), que transcribe correctamente "Searra" y anota la posibilidad de interpretarlo como Segarra, y más recientemente Martínez Díez 
bachiller Tomás de Torquemada y el último para Bernardo de Santa María, presentado en teología y predicador general de la orden. ${ }^{97}$

El perfil dominante en dicha nómina corresponde a intelectuales de reconocido prestigio situados en puestos dirigentes dentro de la orden, con una presencia muy destacada de teólogos originarios o residentes en el convento de Salamanca. Semejante origen permite suponer que se oponían a la Congregación de la Observancia o, como poco, no se identificaban con su causa. Con la salvedad de que no parece proceder de Salamanca, el currículum de Bernardo de Santa María era en todo similar. En total, cinco nombres que debieron ganarse fácilmente la aceptación de Sixto IV y de quienes en la curia pontificia consideraban que, dada la polvareda levantada en Sevilla, el oficio de inquisidor era muy delicado para caer en manos de reformistas radicales más inclinados a la acción que a la reflexión.

Sin embargo, si prescindimos de ese Rodrigo de Seara o Segarra del que nada sabemos, los dos nombres restantes resultan ajenos a las características señaladas, y son por cierto los más importantes de la lista. La presencia de San Cebrián puede explicarse a partir de su papel como intermediario diplomático en la obtención de la bula, de su propia ambición personal (ya había conseguido de forma similar el magisterio en teología) y sobre todo de la estima que despertaba en el pontífice. Por último, Torquemada era un clérigo cortesano ajeno a los ambientes académicos pero de ilustre apellido, miembro además de la Congregación de la Observancia, un detalle nada insignificante; pero su principal activo era la confianza y la cercanía a los reyes, a Fernando en particular, de manera que el papa demostraba con su inclusión el deseo de mantener abiertos los canales de diálogo. ${ }^{98}$

No se trata de una lista hecha al azar o fruto de la parcialidad que cabría esperar de un extremista como San Cebrián, sino cuidadosamente compuesta para que no pudiera ser rechazada - dada la gravedad de sus motivos y la mesura de sus términos-y permitiera conjurar el peligro en que se encontraba la Inquisición regia a causa de la hostilidad del pontífice. El hecho de que siete de sus miembros nunca llegaran a jugar

(Bulario, pp. 92-93), quien transcribe correctamente "Searra" en la versión latina pero en la traducción apuesta de nuevo por Segarra.

97 No conocemos su convento de origen, pero ocupaba un lugar destacado en la orden. En 1479, cuando tomó parte en el proceso contra Osma, ya era calificado como "presentado" (Labajos, Proceso contra Pedro de Osma, p. 119), es decir, alguien que había terminado sus estudios y estaba ad magisterium praesentatus, "esperando el grado de maestro" (RAE, Diccionario de autoridades, http://web.frl.es/ DA.html). En 1483, como hemos visto, ocupó brevemente el cargo de prior de la Provincia. En su carta de confirmación, el maestro general lo calificaba de inquisidor -merced obviamente al nombramiento que aquí nos ocupa- y de predicador general, dos de las dignidades más prestigiosas que podían alcanzarse dentro de la orden (Beltrán, Historia, p. 40-41, n.6).

98 Martínez Peñas (El confesor del rey, pp. 170-171), tratando de establecer si Torquemada fue realmente confesor del rey Fernando, considera que su presencia en esta bula es prueba evidente de la confianza que existía desde antiguo entre ambos, pues el artífice intelectual de la lista de inquisidores había sido San Cebrián, un estrecho colaborador del monarca, quien en el cumplimiento de esta misión no había podido por menos que seguir las instrucciones de su regio patrón. 
un papel destacado en las actividades del Santo Oficio da una idea de la intención con que fue propuesta.

Aún prestaría el vicario otro servicio importante para la supervivencia de la frágil legitimidad jurídica de la nueva Inquisición. El tribunal establecido en Valencia a finales de 1481 se sustentaba sobre la autoridad delegada por el maestro general Salvo Cassetta al dominico leridano Gaspar Jutglar para que pudiera nombrar inquisidores en la Provincia de Aragón. Sin embargo, como consecuencia de la crisis diplomática con la Santa Sede, Cassetta terminó por anular tales poderes, una decisión que el rey Fernando rechazaba en términos amenazadores durante la primavera de 1482, coincidiendo con el estallido del conflicto de Ferrara. ${ }^{99}$ A finales del verano, sin embargo, la posición política del pontífice comenzaba a cambiar y con ella la del maestro general de los dominicos, que a través de Alonso de San Cebrián se mostró dispuesto a reabrir el diálogo con el monarca. El 20 de septiembre, Fernando decía haber recibido por medio del vicario ciertas cartas que fray Salvo le remitía para excusarse por el anterior enfrentamiento. El rey se mostraba dispuesto a acogerlo de nuevo en su gracia y benevolencia, rogándole cuidara con diligencia de los asuntos que pudiera encargarle en el futuro. ${ }^{100}$ De hecho, apenas cinco días después le proponía reformar el convento dominico de Valencia, donde la vida religiosa y académica se encontraba en un lamentable estado de postración debido a la actitud negligente del prior provincial de Aragón. Otras dos cartas sobre el mismo asunto fueron remitidas al vicecanciller Rodrigo de Borja, obispo de Valencia, y al cardenal Oliverio Caraffa, protector de la orden de predicadores, deslizándose en esta última el nombre del vicario San Cebrián, "nostro confessore", como agente de una operación diplomática que esta vez no tuvo consecuencia alguna. ${ }^{101}$

\section{Epílogo (1482-1493)}

De regreso en Castilla, Alonso de San Cebrián acudió al convento de Piedrahita para presidir el capítulo de la Congregación que se celebró entre el 13 y el 15 de noviembre de 1482. Coincidió allí con Tomás de Torquemada, que buscaba la aprobación del proyecto de construcción del convento de Santo Tomás de Ávila, para el que había obtenido una bula pontificia. ${ }^{102}$ Por esas mismas fechas, el vicario recibió un nuevo encargo del rey Fernando que guardaba relación con sus anteriores misiones diplomáticas. Junto con otros tres inspectores debía examinar las cuentas del obispado de Tarazona, cuyas rentas habían sido secuestradas por la Corona durante los años en que la sede estuvo vacante y que era

\footnotetext{
99 Con sendas cartas fechadas el 26 de abril y el 11 de mayo (Torre, Documentos, pp. 212-216).

100 IBIDEM, p. 274; ACA RC 3608, f. 45v.

101 Torre, Documentos, pp. 276-277; ACA RC 3608, ff. 26v-27.

102 LóPez, Tercera parte, pp. 274-275; Cienfuegos, Breve reseña histórica, pp. 15-16; Meseguer, "El periodo fundacional”, p. 310, n. 74. La bula de Santo Tomás de Ávila había sido otorgada por Sixto IV el 23 de noviembre de 1480 (Bullarium, t. III, p. 594).
} 
preciso saldar antes de que tomara posesión el nuevo titular. ${ }^{103}$ La participación de San Cebrián -calificado para la ocasión como confesor del rey y "general de los dominicos observantes en la Provincia de Castilla"- en un negocio eminentemente técnico, no guardaba relación tanto con su pericia contable, de la que no se tiene otra noticia, como con la necesidad de ofrecer garantías al nuevo obispo, Andreu Martínez Ferris, miembro de la cancillería pontificia y sobrino del anterior titular, el cardenal valenciano Pere Ferris, cuya toma de posesión venía bloqueando Fernando desde 1478 y que finalmente reconoció como parte del acuerdo con el papa. ${ }^{104}$ Eran las dotes diplomáticas de San Cebrián y sus buenas relaciones con Sixto IV las que otra vez hacían de él un intermediario cualificado.

No hay noticia alguna de que fuera reelegido como vicario de la observancia en 1482 o 1483. Beltrán de Heredia no desestima la posibilidad de que continuara ejerciendo su cargo en virtud de la prórroga otorgada en Roma por el maestro general Cassetta, que no tenía fecha de vencimiento, hasta que en 1484 fue sustituido por Vicente de Córdoba. ${ }^{105}$ De ser así, el relevo de San Cebrián se habría producido en los últimos días del año, porque un documento regio fechado el 22 de diciembre de 1484 todavía le otorgaba el título de "vicario general del orden de Sancto Domingo de observança en el reyno nuestro de Castilla". ${ }^{106}$

Sí es seguro que reanudó sus campañas reformistas apenas regresó de Italia. Otra carta real, fechada en Valladolid el 23 de junio de 1486, da cuenta de sus actividades. ${ }^{107}$ Era por entonces prior del convento de San Pablo de Valladolid - cargo al que habría accedido tras dejar la vicaría a finales de 1484 o principios de 1485 - y desde hacía "dos o tres años" se dedicaba a reformar los conventos femeninos de la orden para integrarlos en la Congregación. Los reyes le habían otorgado en su día los poderes necesarios para hacerlo, afirmando que con ello no hacían sino cumplir las órdenes del papa. ${ }^{108}$ Así, entre mediados de 1483 y mediados de 1484 , cuando todavía era vicario

\footnotetext{
${ }_{103}$ Según la carta real con la que Fernando aprobaba las cuentas de los administradores, fechada en Madrid el 15 de diciembre de 1482 (ACA RC 3608, f. 32). El asunto se despachó en un nivel alto de representación política, con participación en el equipo inspector de dos miembros destacados de la cancillería catalano-aragonesa, los secretarios Gaspar de Arinyo y Luis González, así como de un verdadero experto en contabilidad, Juan Granada, que andando el tiempo se convertiría en el primer "contador general" de las inquisiciones de la Corona de Aragón (Cruselles, "La primera contabilidad inquisitorial", pp. 238-239). Tanto Granada como San Cebrián intervenían por parte del nuevo obispo, a quien es muy probable que el vicario hubiera conocido personalmente en su reciente viaje a Roma.

${ }^{104}$ Que fue asimismo un acuerdo con el entorno borgiano de la curia pontificia al que estaba vinculado Martínez Ferris, e incluyó la cesión al vicecanciller Borja de la sede de Cartagena, a la que los reyes también se habían resistido al principio (Cruselles, "El cardenal Rodrigo de Borja”, pp. 263 y 266).

105 Beltrán, Historia, p. 25-27.

106 En aquel momento seguía desempeñando algún tipo de misión para el rey Fernando, que "de mandamiento verbal" ordenaba a Gabriel Sánchez, tesorero general de la Corona de Aragón, entregarle 30.000 maravedís (1.760 sueldos jaqueses) para distribuir en limosnas (ACA RC 3616, f. 23).

107 AGS RGS 1486-VI, n ${ }^{\circ}$ 122. El documento fue autorizado por Pedro Fernández de Velasco, condestable de Castilla, y otros miembros del consejo real, pues los monarcas no se encontraban en Valladolid sino en tierras granadinas, siguiendo las operaciones bélicas (Romeu de ARMAS, Itinerario, p. 141).

108 No se cita ningún documento pontificio específico al respecto, pero en propiedad la bula Sedis Apostolicae circunspecta había dejado todos los conventos de la orden a merced de los reformadores observantes
} 
de la observancia, había reformado el convento femenino de San Cebrián de Mazote, una localidad situada cuarenta kilómetros al oeste de Valladolid, cambiando a la priora, la subpriora "e los otros ofiçios nesçesarios a la oserbança e ençerramiento del dicho monasterio e lo dexó asy reformado". Sin embargo, un tiempo después habían surgido problemas. Una parte de la comunidad rechazaba la observancia y, "con induzión de algunas personas", había depuesto a la priora y se negaba a obedecer a San Cebrián. Este, fiel a su método, reclamó gente armada al consejo real, que le envió un alguacil para restablecer el orden en el convento, llevarse presos a quienes hubieran apoyado a las monjas rebeldes y amenazar al resto de la población con graves penas pecuniarias si les volvían a prestar ayuda "asy en público como en secreto". La advertencia se hizo extensiva a los lugares vecinos de Torrelobatón, Urueña, Mota del Marqués y Adalia.

Es posible que fueran precisamente sus maneras expeditivas las que aconsejaron mantener apartado a San Cebrián de las negociaciones para reformar el convento de San Esteban de Salamanca, sin duda el mayor éxito obtenido por la Congregación en aquellos años, a pesar de que la bula pontifica que justificaba la maniobra le había sido otorgada personalmente por Sixto IV, y solo por extensión a sus sucesores al frente de la vicaría. Los impulsores del proyecto fueron Vicente de Córdoba y Tomás de Torquemada, a quienes la reina Isabel encomendó la reforma de San Esteban con un mandamiento expedido en Córdoba el día 9 de junio de $1486 .{ }^{109} \mathrm{El}$ talante moderado de fray Vicente, nuevo vicario de la observancia, su condición de hijo de hábito del cenobio salmantino y también las condiciones políticas en que se encontraba el país, muy distintas a las que existían en 1475 cuando San Cebrián asaltó el convento, facilitaron un pacto con el prior Diego Magdaleno y una parte mayoritaria de la comunidad. Ni siquiera el prior provincial Juan del Espíritu Santo, profeso también de San Esteban, presentó mucha oposición. ${ }^{110}$ Parece razonable pensar que, tras la caída de Andrés de Toro, se había abierto camino, en la conciencia de las autoridades de la Provincia y de los frailes de los principales conventos, la convicción de que la victoria final de la Congregación era inevitable. De hecho, a principios del siglo XVI la Congregación de la Observancia y la Provincia Dominicana de España se fusionaron bajo el control de la primera, pasando el vicario de aquella a convertirse en prior provincial. ${ }^{111}$

A principios de 1487, siendo aún prior de Valladolid, San Cebrián recibió de los reyes el último encargo del que tenemos noticia. Junto con Juan Arias Dávila, obispo de

\footnotetext{
(véase n. 66).
}

109 Cuervo, Historiadores, vol. II, pp. 497-498. Ocurrió quince días antes de que el consejo real, desde Valladolid, enviara ayuda al exvicario para someter a las monjas de San Cebrián de Mazote. Algunos cronistas dominicos aventuran la participación de San Cebrián en la reforma del convento de Salamanca (LóPEz, Tercera parte, p. 171), pero la carta de la reina tan solo se refiere a él como destinatario de la bula pontificia y no lo incluye entre quienes reclamaron el apoyo de la Corona. Por su parte, los historiadores del convento de San Esteban no mencionan a San Cebrián en relación con este asunto.

110 Nieva, "La creación de la observancia regular", pp. 101-105.

111 En mayo de 1504 Diego Magdaleno, antiguo prior de San Esteban de Salamanca, fue elegido vicario de la Congregación y unos meses después el maestro general de la orden cesó al prior provincial y puso a Magdaleno al frente de la Provincia (Beltrán, Historia, pp. 55-56). 
Segovia, debía investigar la denuncia presentada ante la corte regia contra cierto fray Francisco de Bovadilla, que había realizado algunas enajenaciones fraudulentas de bienes muebles e inmuebles mientras actuaba como administrador del convento de Santa María la Real de Tordesillas. ${ }^{112}$ Otras informaciones biográficas relativas a los últimos años de vida de Alonso de San Cebrián, que aparecen dispersas en las crónicas dominicanas, resultan contradictorias y se resisten a cualquier verificación documental. Comenzando por su participación en las primeras actividades de la Inquisición española. Antonin Brémond afirma que Torquemada, una vez convertido en inquisidor general, designó inquisidores delegados en diversos tribunales y que el elegido para Valladolid fue San Cebrián. ${ }^{113}$ Por su parte, Beltrán de Heredia pone en duda la identificación con otro Alonso de San Cebrián que a finales de 1492 fue nombrado obispo libariense in partibus infidelium por Alejandro VI, dado que este era presentado en teología y no magister como el exvicario. ${ }^{114} \mathrm{Su}$ muerte debió producirse por estas fechas, a lo más tardar en 1493 según el propio Beltrán, porque fue consignada en las actas del capítulo que los observantes celebraron ese año en Toledo:

"En el convento de Sevilla [murió] el R.P. de gloriosa memoria el maestro fray Alonso de San Cebrián, primer fundador de nuestra Congregación, que fue durante mucho tiempo vicario general de nuestra Congregación y tantos esfuerzos hizo por ella y por la reforma de los conventos." 115

El hecho de que muriera en Sevilla hizo pensar a Beltrán que, en los últimos años de su vida, el exvicario pudo tener alguna participación en la reforma de los conventos andaluces, pero no ofrece más información al respecto. Por su parte, el cronista José Barrio, por lo general bien informado, afirmaba a principios del siglo XVIII que aquel capítulo de la Congregación se había celebrado a mediados del mes de abril de 1493, siendo vicario general fray Juan de Yarza, pero en Toro y no en Toledo. También parafraseaba el párrafo anterior de las actas para advertir que en aquella reunión se había anunciado la muerte de San Cebrián, "primer vicario y fundador de la Congregación reformada", por la que "padeció muchos trabajos"; sin embargo, el luctuoso suceso

\footnotetext{
112 AGS. RGS. 1487-II, no 93.

113 Junto con cierto presentado en teología llamado Bartolomé Feral. Los demás tribunales eran los de Sevilla, Toledo, Jaén y Ávila (Bullarium, t. III, p. 622). El texto de Brémond fue tomado literalmente del cronista Vincenzo Fontana, quien a su vez se remitía a Páramo y a los Annales ecclesiastici de Bzovius y Spondanus (Fontana, Monumenta dominicana, p. 378), aunque ninguno de estos recoge de hecho semejante información.

114 Beltrán, Historia, p. 26, n. 31. Este nombramiento también lo recogió Brémond (Bullarium, t. IV, p. 193). La diócesis en cuestión era la de Lirba, ciudad situada en la región de Panfilia, en el sur de Anatolia (Fort, Obispos españoles, p. 181).

115 Beltrán, Historia, pp. 25-26; la traducción es nuestra.
} 
habría tenido lugar en el convento de Valladolid y no en el de Sevilla. ${ }^{116}$ Dos versiones distintas sobre las que, de momento, no podemos pronunciarnos.

En los años siguientes, la Congregación contó con otros dirigentes tan extremistas o más que San Cebrián, como Pascual de Ampudia y sobre todo Antonio de la Peña, que alcanzaron también cierta influencia en la corte regia. Lo que confiere singularidad a la figura política de San Cebrián es el momento en que surgió, una época marcada por los conflictos internos en la que Isabel y Fernando estaban dispuestos a recurrir a los medios más expeditivos para afianzarse en el trono. En este sentido, el vicario formó parte de aquel grupo de eclesiásticos que, convertidos en agentes de la monarquía durante los años de la guerra civil, contribuyeron a sujetar a su autoridad las instituciones religiosas. Su campo de acción fue una orden dominicana cuyo gobierno, como el de las otras órdenes, intentaron controlar los reyes aliándose con las facciones observantes, minoritarias pero igualmente expeditivas en sus métodos. Sin embargo, la violencia no era suficiente. La certeza de que, en último término, el enfrentamiento contra los "claustrales" debía resolverse jurídicamente en las instancias superiores de la orden y en la curia pontificia, condujo a San Cebrián a poner en juego unas dotes diplomáticas que, en combinación con el apoyo decidido de la monarquía, le condujeron de éxito en éxito. En este ámbito, el particular vínculo que los dominicos mantenían con la Inquisición hizo de él un intermediario adecuado para algunas misiones que, en un momento de fuerte tensión entre la monarquía y la Santa Sede, contribuyeron a evitar que se desmantelara el frágil armazón institucional de un Santo Oficio apenas naciente. No podemos asegurar que contribuyera directamente en la obtención de la bula fundacional de 1478, aunque existen algunos indicios al respecto, pero sin duda sus buenos oficios fueron decisivos para conseguir el nombramiento de los ocho inquisidores en $1482 \mathrm{y}$, por extensión, para que la carrera de Torquemada como primer inquisidor general pudiera dar comienzo.

\section{Bibliografía}

Azcona, Tarsicio de, "La reforma religiosa y la confesionalidad católica en el reinado de Isabel I de Castilla, la Católica", Carthaginensia. Revista de estudios e investigación, 31 (2015), pp. 111-136.

Azcona, Tarsicio de, "Las asambleas del clero de Castilla en el otoño de la Edad Media”, Miscelánea José Zunzunegui (1911-1974), Editorial ESET, Vitoria, 1975, vol. I, pp. 203-245.

Azcona, Tarsicio de, Isabel la Católica: estudio crítico de su vida y su reinado, Editorial Católica, Madrid, 1964.

\footnotetext{
116 Cuervo, Historiadores, vol. II, pp. 504-505. En otra parte de su libro, Beltrán (Historia, pp. 32-34) hace un resumen de las actas del capítulo de la Congregación celebrado en Toro en abril de 1493, sin duda las mismas actas que menciona Barrio, aunque no advierte que ese mismo año se hubiera producido una segunda reunión en Toledo.
} 
Barrio Gozalo, M., "La iglesia de Segovia durante el pontificado de Arias Dávila (1461-1497). Instituciones y poder económico", Segovia en el siglo XV. Árias Dávila: obispo y mecenas, A. Galindo García (ed.), Universidad Pontificia de Salamanca, Salamanca, 1998, pp. 77-98.

Beltrán de Heredia, Vicente, Historia de la Reforma de la Provincia de España (14501550), Institutum Historicum FF. Praedicatorum, Roma, 1939.

Beltrán de Heredia, Vicente, "Nebrija y los teólogos de San Esteban de principios del siglo XVI", Miscelánea Beltrán de Heredia, vol. I, Editorial OPE, Salamanca, 1971, pp. 443-468.

Beltrán de Heredia, Vicente, "Los comienzos de la reforma dominicana en Castilla, particularmente en el convento de S. Esteban de Salamanca y su irradiación a la Provincia de Portugal". Miscelánea Beltrán de Heredia. Colección de artículos sobre historia de la teología española, Editorial OPE, Salamanca, 1971, vol. I, pp. 403-425.

Bullarium Ordinis FF. Praedicatorum, tomus tertius. Ab anno 1430 ad 1484, Antonin Brémond (ed.), Girolamo Mainardi, Roma, 1731.

Bullarium Ordinis FF. Praedicatorum, tomus quartus. Ab anno 1484 ad 1549, Antonin Brémond (ed.), Girolamo Mainardi, Roma, 1732.

CABré, María Dolores, "El arzobispo de Tarragona, Gonzalo Fernández de Heredia", Cuadernos de historia Jerónimo Zurita, 47-48 (1983), pp. 299-321.

Calmette, Joseph, "La politique espagnole dans la guerre de Ferrare (1482-1484)", Revue historique, 31 (1906), pp. 225-253.

Cienfuegos, Cayetano G., Breve reseña histórica del Real Colegio de Santo Tomás de Ávila, Imprenta de L. Aguado, Madrid, 1895.

Colombás, García M., Las Señoras de San Payo. Historia de las monjas benedictinas de San Pelayo de Antealtares, Caja de Ahorros de Galicia, Santiago de Compostela, 1980.

Cruselles Gómez, José Ma, "El Cardenal Rodrigo de Borja, los curiales romanos y la política eclesiástica de Fernando II de Aragón", De la unión de coronas al Imperio de Carlos V. Congreso internacional, Barcelona 21-23 de febrero de 2000, E. Belenguer Cebrià (coord.), Sociedad Estatal para la Conmemoración de los Centenarios de Felipe II y Carlos V, Madrid, 2001, pp. 253-280.

Cruselles Gómez, José Ma " "La primera contabilidad inquisitorial. El fondo del Archivo del Reino de Valencia (1482-1527)", En el primer siglo de la Inquisición española. Fuentes documentales, procedimientos de análisis, experiencias de investigación, J. M. Cruselles Gómez (coord.), Publicaciones de la Universidad de Valencia, Valencia, 2013, pp. 221-250.

Cruselles Gómez, José Ma "'Llegan los inquisidores. Los primeros momentos del tribunal valenciano del Santo Oficio", Joan Roís de Corella i el seu món, Institució Alfons el Magnànim, Valencia, 2014, pp. 109-136. 
Cruselles Gómez, José Ma " "Fernando el Católico, la familia Borja y la nueva Inquisición", Normes, marges, confins. Hommage au professeur Raphaël Carrasco, Presses universitaires de la Méditerranée, Montpellier, 2018, vol. I, pp. 27-46.

Cuervo, Justo, Historiadores del convento de San Esteban de Salamanca, 3 vols., Imprenta Católica Salmanticense, Salamanca, 1914-1915.

Diago, Francisco, Historia de la Provincia de Aragón de la Orden de Predicadores, Provincia Dominicana de Aragón, Barcelona, 1599. [Ed. facsímil: Librerías París-Valencia, Valencia, 1999.]

DíAz IBÁÑEz, Jorge, "Fray Alonso de Burgos. Un prelado al servicio de la monarquía castellana en la segunda mitad del siglo XV", Ecclesiastics and Political State Building in the Iberian Monarchies, 13th-15th Centuries, H. Vasconcelos Vilar y M. João Branco (dirs.), Publicações do Cidehus, Évora, 2016, pp. 147-182.

Enseñat de Villalonga, Alfonso, "La noble, acaudalada y poderosa familia genovesa Centurione Canelli y su largo asentamiento en España (1375-1492)", Hidalguía, 348 (2011), pp. 581-610.

FITA, Fidel, "La verdad sobre el martirio del Santo Niño de la Guardia, o sea, el proceso y quema (16 de noviembre de 1941) del judío Jucé Franco en Ávila", Boletín de la Real Academia de la Historia, 11 (1887), pp. 7-134.

FitA, Fidel, "Nuevas fuentes para escribir la historia de los judíos españoles. Bulas inéditas de Sixto IV e Inocencio VIII", Boletín de la Real Academia de la Historia, 15 (1889), pp. 442-491.

Fors, Mario, "La questione degli studi nell'Osservanza e la soluzione di S. Bernardino da Siena", Atti del simposio internazionale cateriniano-bernardiniano: Siena, 17-20 aprile 1980, Accademia Senese degli Intronati, Siena, 1982, pp. 477-497.

Fontana, Vincenzo Maria, Monumenta dominicana breviter in synopsim collecta, de fidis obsequiis ab ordine praedicatorum Sanctae Dei Ecclesiae usque modo prestitis, Nicolò Angelo Tinassi, Roma, 1675.

FORT, Carlos Ramón, Obispos españoles titulares de iglesias in partibus infidelium o auxiliares en la de España, Real Academia de la Historia, Madrid, 1879 (España Sagrada, t. 51).

Fuertes Herreros, José Luis, "Contra el nominalismo. Humanismo y renovación de la filosofía y teología en Pedro Martínez de Osma (1424-80)", Revista española de filosofía medieval, 11 (2004), pp. 243-256.

Fuertes Herreros, José Luis, "La estructura de los saberes en la primera Escuela de Salamanca", Cauriensia. Revista anual de ciencias eclesiásticas, 6 (2011), pp. 103-145. GARCía Oro, José, "La reforma de los monasterios gallegos en tiempos de los Reyes Católicos”, Cuadernos de estudios gallegos, 21 (1966), pp. 42-58. 
García Oro, José, “Conventualismo y observancia. La reforma de las órdenes religiosas en los siglos XV y XVI”, Historia de Iglesia en España, tomo III, J. L. González Novalín (dir.), Biblioteca de Autores Cristianos, Madrid, 1980, vol. I, pp. 211-349.

GARcía Oro, José, "La reforma religiosa y su repercusión en la vida social española. Balance historiográfico", Isabel la Católica y su época. Actas del Congreso Internacional (Valladolid-Barcelona-Granada, 2004), Universidad de Valladolid, Valladolid, 2007, vol. II, pp. 1107-1113.

Grendler, Paul F., The Universities of the Italian Renaissance, The Johns Hopkins University Press, Baltimore, 2001.

GuERrA, Enrica, Soggetti a "ribalda fortuna”. Gli uomini dello stato estense nelle guerre dell'Italia quattrocentesca, Franco Angeli, Milán, 2005.

Herrero del Collado, Tarsicio, "El proceso inquisitorial por delito de herejía contra Hernando de Talavera”, Anuario de historia del derecho español, 39 (1969), pp. 671-706.

IANNuZzI, Isabella, "La condena a Pedro Martínez de Osma: «ensayo general» de control ideológico inquisitorial”, Investigaciones históricas. Época moderna y contemporánea, 27 (2007), pp. 11-46.

Labajos Alonso, José, Proceso contra Pedro de Osma, Universidad Pontificia de Salamanca, Salamanca, 2010.

Larios Ramos, Antonio, “Los dominicos y la Inquisición”, Clio\&Crimen, 2 (2005), pp. 81-126.

LlorCA, Bernardino, Bulario pontificio de la Inquisición española en su periodo constitucional (1478-1525), Pontificia Università Gregoriana, Roma, 1949.

Llorente, Juan Antonio, Memoria histórica sobre qual ha sido la opinión nacional de España acerca del tribunal de la Inquisición, Gérard Dufour (ed.), Presses Universitaires de France, París, 1977.

LóPEz, Juan, Tercera parte de la Historia general de Sancto Domingo y de su Orden de Predicadores, Francisco Fernández de Córdova, Valladolid, 1613.

Lorente Toledo, Luis, San Pedro Mártir el Real, conventual y universitario. Siglos XIII-XIX. Toledo, Universidad de Castilla-La Mancha, Ciudad Real, 2002.

Martínez Díez, Gonzalo, Bulario de la Inquisición española hasta la muerte de Fernando el Católico, Editorial Complutense, Madrid, 1997.

Martínez Peñas, Leandro, El confesor del rey en el Antiguo Régimen, Editorial Complutense, Madrid, 2007.

Meseguer Fernández, Juan, "El periodo fundacional: los hechos”, Historia de la Inquisición en España y América, B. Escandell y J. Pérez Villanueva (eds.), Biblioteca de Autores Cristianos, Madrid, 1984, vol. I, pp. 281-369.

Miura Andrades, José María, "La Provincia Bética de la Orden de Predicadores durante la Baja Edad Media. Los frailes”. Revista de Humanidades, 27 (2016), pp. 19-42. 
Mortier, Antonin, Histoire des Maîtres Généraux de l'Ordre des Frères Prêcheurs, tomo IV, A. Picard, París, 1914.

Nieto Soria, José Manuel, Iglesia y génesis del estado moderno en Castilla (1369-1480), Editorial Complutense, Madrid, 1993.

Nieva OcAmpo, Guillermo, "La creación de la observancia regular en el convento de San Esteban de Salamanca durante el reinado de los Reyes Católicos", Cuadernos de historia de España, 80 (2006), pp. 91-126.

Nieva Ocampo, Guillermo, "Reformatio in membris: conventualidad y resistencia a la reforma entre los dominicos de Castilla en el siglo XV", En la España Medieval, 32 (2009), pp. 297-341.

Nieva OcAMPo, Guillermo, "La observancia dominica y la monarquía castellana: compromiso político y disciplinamiento social (1460-1550)", La corte en Europa: política y religión (siglos XVI-XVIII), J. Martínez Millán, M. Rivero Rodríguez y G. Versteegen (coords.), Polifemo, Madrid, 2012, vol. I, pp. 513-561.

Nieva OcAmpo, Guillermo, "De la colaboración a la oposición: los frailes dominicos y la realeza castellana (1370-1474)", Erasmo. Revista de Historia Bajomedieval y Moderna, 3 (2016), pp. 89-99.

Olmedo, Félix G., Nebrija (1441-1522). Debelador de la barbarie, comentador eclesiástico, pedagogo, poeta, Editora Nacional, Madrid, 1942.

PÁramo, Luis de, De Origine et progressu Officii Sanctae Inquisitionis, Typographia Regia, Madrid, 1598.

Pérez García, Pablo, “La Inquisición y el libro antes de la Inquisición: el procesamiento de fr. Pedro de Osma”, En el primer siglo de la Inquisición española. Fuentes documentales, procedimientos de análisis, experiencias de investigación, J. M. Cruselles Gómez (coord.), Publicaciones de la Universidad de Valencia, Valencia, 2013, pp. 65-80. PÉREZ VIDAL, Mercedes, “Observancia y rigorismo. Consecuencias de la reforma de La Orden de Predicadores y de algunos movimientos rigoristas en la liturgia y arquitectura de los monasterios de dominicas de la «Provincia de España»", Literatura medieval y renacentista en España. Líneas y pautas, N. Fernández Rodríguez y M. Fernández Ferreiro (coords.), Universidad de Salamanca, Salamanca, 2012, pp. 801-812.

Pinta Llorente, Miguel de la, La Inquisición española, Archivo Agustiniano, Madrid, 1948.

Prieto SAyagués, Juan Antonio, “El acercamiento de la monarquía castellana a la Orden de Predicadores durante el reinado de Juan II de Castilla (1406-1454)", En la España Medieval, 39 (2016), pp. 197-224.

Pulgar, Fernando del, Crónica de los señores Reyes Católicos don Fernando y doña Isabel de Castilla y Aragón, Imprenta de Benito Monfort, Valencia, 1780.

Pulgar, Fernando del, Claros varones de Castilla; y Letras, Ortega é hijos de Ibarra, Madrid, 1789. 
RÁbade Obradó, María del Pilar, Una elite de poder en la corte de los Reyes Católicos: los judeoconversos, Editorial Sigilo, Madrid, 1993.

Romeu de Armas, Antonio, Itinerario de los Reyes Católicos, 1474-1516, CSIC, Madrid, 1974.

Serrano Rodríguez, Eugenio, Toledo y los dominicos en la época medieval. Instituciones, economía, sociedad, Universidad de Castilla-La Mancha, Cuenca, 2014.

Sesma Muñoz, José Ángel, Fernando II y la Inquisición. El establecimiento de los tribunales inquisitoriales en la Corona de Aragón (1479-1490), Real Academia de la Historia, Madrid, 2013.

SuÁrez Fernández, Luis, Política internacional de Isabel la Católica. Estudio y documentos, 2 vols., Instituto Isabel la Católica de Historia Eclesiástica, Valladolid, 1965.

TORRE Y DEL CERro, Antonio de la, Documentos sobre relaciones internacionales de los Reyes Católicos, I. 1479-1483, CSIC, Barcelona, 1949.

Waltz, Angelus Maria, Compendium historiae Ordinis Praedicatorum, Herder, Roma, 1930. 